\title{
Analisis Molekular dan Karakteristik Hidrogen Sianida $(\mathrm{HCN})$
}

\author{
Aulia Dinul Husna ${ }^{1}$, Rahadian Zainul ${ }^{* *}$ \\ ${ }^{1}$ Pendidikan Kimia, FMIPA, Universitas Negeri Padang, Indonesia \\ ${ }^{2 *}$ Physical Chemistry Laboratory, FMIPA, Universitas Negeri Padang, Indonesia \\ *E-mail : auliaaulia693@gmail.com \\ rahadianzainul@yahoo.com
}

1. Abstrak. Hidrogen sianida dalam air membentuk asam lemah bersifat toksik. Tujuan review ini untuk menganalisis molekular dan transpor elektron hidrogen sianida. Metode yang digunakan adalah penggambaran molekul dengan aplikasi Chem Office versi 15.0 , untuk mengetahui transpor ion asam sianida yaitu dengan parameter konduktivitas, viskositas, mobilitas ion, dan gerakan hanyut.Hasil yang didapat yaitu struktur molekul asam sianida pada analisis molekuler 2D, dan bentuk molekul asam sianida dalam 3D. Berdasarkan metode ini diperoleh energi kinetik rotasi senyawa $2,0466 \mathrm{kcal} / \mathrm{mol}$. Untuk konduktivitas, kecepatan hanyut, gerakan ion,dilakukan dengan menggunakan metode perhitungan dengan rumusan hasilnyadan beberapa soal yang dibuatkan grafiknya Analisis jari-jari atom hidrogen dengan carbon pada Chemdraw 3D didapatkan sebesar 1,1 A, dan jari jari atom carbon dengan nitrogen masing-masingnya sebesar $1,1 \mathrm{~A}$. Data yang didapat pada Analisa MM2 dynamics $\mathrm{HCN}$ adalah interaction time $0.024,0.026,0.028,0.030$, total energy $0.048,0.082$, potensial energy $0.38,0.045,0.016,0.091$.sifat dari asam sianida diantaranya massa molar 27,03 g/mol, densitas $0,687 \mathrm{~g} / \mathrm{mL}$, viskositas : $201 \mu \mathrm{Pa}$ s. Sifat termodinamika hidrogen sianida adalah $\Delta \mathrm{G}$ (enegi gibs) $143,1 \mathrm{kj} / \mathrm{mol}$ entropi $(\Delta \mathrm{S}) 113,01 \mathrm{~J} / \mathrm{kmol}$, entalpi pembentukan standar $\left(\Delta_{\mathrm{f}} \mathrm{H}\right)-141,2 \mathrm{~kJ} / \mathrm{mol}$, entalpi pembakaran standar $\left(\Delta_{\mathrm{c}} \mathrm{H}\right)$ $426,5 \mathrm{~kJ} / \mathrm{mol}$ dan kecepatan hanyut yang didapat berdasarkan perhitungan sebesar $2,33 \mathrm{~V} / \mathrm{cm}$.

Kata kunci : Asam sianida, transfer elektron

\section{I.Pendahuluan}

Asam sianida ${ }^{(1-40)}$ adalah senyawa kimia yang mengandung gugus siano $\mathrm{C} \equiv \mathrm{N}$ yang terikat dengan atom hidrogen ${ }^{(7 ; 10 ; 26 ; 27 ; 32 ; 41-45)}$, atom karbon terikat tiga ke atom nitrogen. Pada gugus $\mathrm{CN}$ sebagai ion sianida poliatomik yang bermuatan negatif $\left(\mathrm{CN}^{-}\right)$. Hidrogen Sianida salah satu senyawa yang sangat beracun. Anion $\mathrm{CN}$ - bersifat isoelektronik jika berikatan dengan molekul nitrogen dan karbon monoksida.

Umumnya Sianida organik juga disebut nitril, dimana terdapat ikatan kovalen pada gugus CN dengan gugus, seperti metil $\left(-\mathrm{CH}_{3}\right)$ pada metil sianida (asetonitril). Pada umumnya nitril tidak melepas ion sianida maka bersifat tidak beracun, kecuali jika dibakar. Senyawa Asam ${ }^{[203]}$ Sianida merupakan cairan yang mudah menguap ${ }^{[207]}$.

Metode oksidasi Andrussow yang diciptakan oleh Leoinid Andrussow menjelaskan proses pembuatan asam sianida $(\mathrm{HCN})$ yang paling sering dilakukan menggunakan metode, yang diciptakan oleh Leonid Andrussow, dimana metana ${ }^{(155-174)}$, dan amonia bereaksi pada suhu ${ }^{[206]}$ sekitar $1200^{\circ} \mathrm{C}$ menggunakan katalis platina ${ }^{(175-194)}$, dengan reaksi sebagai berikut : 


$$
2 \mathrm{CH}_{4}+2 \mathrm{NH}_{3}+3 \mathrm{O}_{2} \rightarrow 2 \mathrm{HCN}+\mathrm{H}_{2} \mathrm{O}
$$

Energi yang dibutuhkan untuk reaksi ini berasal dari panas yang timbul akibat reaksi oksidasi parsial metana dan amonia.

Proses pembuatan HCN lainnya adalah proses Degussa (BMA proses) dimana tidak ada oksigen ditambahkan dan energi harus ditransfer secara tidak langsung melalui dinding reaktor, dengan reaksi sebagai berikut :

$$
\mathrm{CH}_{4}+\mathrm{NH}_{3} \rightarrow \mathrm{HCN}+3 \mathrm{H}_{2}
$$

Asam hidrosianat ( $\mathrm{HCN}$ ) juga bisa diekstrak dar daun, bunga, atau umbi-umbian dari tanaman beracun yan memiliki cyanohydrins, dengan cara hidrolisis yang diikuti proses pengasaman dan penyulingan.

Sianida memiliki peran yang sangat penting dalam ekstraksi emas berukuran mikro dan nano batuan asalnya. Umumnya jenis sianida yang digunakan dalam proses ekstraksi emas ${ }^{(128-153)}$ adalah alkali sianida, yang bisa berupa senyawa $\mathrm{NaCN}$ atau $\mathrm{KCN}$

$$
4 \mathrm{Au}_{(\mathrm{s})}+8 \mathrm{Na}^{+}{ }_{(1)}+\mathrm{O}_{2}+\mathrm{H}_{2} \mathrm{O} \rightarrow 4 \mathrm{Na}\left[\mathrm{Au}(\mathrm{CN})_{2(1)}+4 \mathrm{NaOH}\right.
$$

Berdasarkan reaksi diatas, logam emas larut dalam ion sianda, membentuk anion kopleks $4 \mathrm{Na}\left[\mathrm{Au}(\mathrm{CN})_{2(1)}\right.$. Larutan emas ini selanjutnya diadsorbsi menggunakan adsorbent karbon aktif atau granular resin(195-200) anion yang bisa dipisahkan dari lumpur melalui proses penyarigan partikel kasar . Disamping NaCN dan KCN, ion kompleks heksasianoferaat III juga bisa digunakan sebagai oksidator dan pelarut emas dalam proses sianidasi. Senyawa ferri sianida dan ferrosianida memeiliki tingkat toksik yang relatif rendah dibanding senyawa alkali sianida yang lain, disebabkan ikatan antara ion besi II dan besi III dan ion sianida yang jauh lebih uat. Namun perubahan PH yang erjadi akibat naiknya konsentrasi ion hidrogen dalam larutan ferrri atau ferro sianida dapat melepaskan senyawa hidrogen sianida yang bercun dari larutanya.

Prussian Blue atau zat kimia biru prussia merupakan pigmen biru tua dengan ruus kima yang ideal $\mathrm{Fe}_{7}(\mathrm{CN})_{18}$. Prussian Blue dibuat dari reaksi kimia antarra larutan alkali ferro-sianida dan laruta jenuh besi III klorida. Kombinasi dari ion feerri berasal larutan jenuh besi III klorida dan ion ferro sianida membentk pgmen warna yang memiliki warna biru tua. Prussian Blue bersifat non-toksik (tidak beracun) dan justru digunakan sebgai obat.

Prussian Blue juga digunakan secara luas dalam berbagai bidang . Pengguanaan terbesar dari pigmen ini adalah industri ca dan tinta cair, pembiru pakaian putih saat dibilas (blau). Prussian Blue juga digunakan sebagai obat bagi beberapa jenis keraacunana logam berat, misalnya keracuan yang disebabkan oleh logam thalium dan isotop radoaktif cesium, untuk pengobatan keracunan.

\section{Metode}

Asam sianida secara makroskopik ${ }^{(71-73)}$ berwujud cair . Untuk itu, pengkajian secara mikroskopik seperti bentuk molekul, karakteristik serta interaksi yang terjadi sangat dibutuhkan guna mengenalinya lebih dalam. Pada perolehan yang menggunakan literasi jurnal disitasi melalui aplikasi EndNote dan menghasilkan fishbone state of art.Pada analisa molekular, maka dilakukan metode komputasi $^{(74)}$ atau permodelanmenggunakan aplikasi ChemOffice 15.0 dimana sub aplikasi yang digunakan yaitu ChemDraw professional 15.0 untuk molekul 2D dan Chem3D 15.0.

Pengolahan data dapat dilakukan melalui beberapa tahapan diantaranya:

(1) Analisis molekul HCN secara dua dimensi menggunakanChemDraw professional $15.02 \mathrm{D}$;

(2) Analisis molekul ${ }^{(75)}$ secara tiga dimensi dengan ChemDraw professional 15.0 2D yang diproyeksikan pada Chem 3D. Pemodelan ini dengan mengasumsikan pada satu molekul HCN dengan beberapa kemungkinan pergerakan dan vibrasional yang terjadi ${ }^{(76 ; 77)}$. 
Molekul HCN mulanya digambarkan pada software dari ChemDraw professional 15.0 2D dengan cara klik Structure, pilih bagian bawah "Convert Name to Structure”. Setelah itu muncul pada layar kerja, tulis boric acid, lalu pilih OK. Setelah rumus molekul terbentuk, lakukan analisis senyawa. Proses analisisa dilakukan pada bagian View, dengan optional show analysis window dan show chemical properties windows.

Pada analisisamolekul secara 3D dilakukan dengan merubah molekul 2D ke Chem 3D. Pada bagian Chem 3D, struktur HCN menjadi tiga dimensi dan dapat dianalisis keadaan sebelum optimasi dengan pilihan select, sesuai pengukuran dan observasi yang diinginkan.

Analisa molekular melalui aplikasi bertujuan untuk mengetahui bentuk molekul, ${ }^{(223-225)}$ jenis ikatan pada molekul, pergerakan molekul, ${ }^{(78-80)}$ energi yang dihasilkan molekul tersebut serta bagian-bagian lainnya yang tidak dapat diamati secara langsung oleh mata tanpa bantuan alat. Data yang diperoleh berupa gambar molekular 2D dan 3D. Selain itu, melalui ChemOffice 15.0 diperoleh optimasi MM2 pada HCN. Data yang diperoleh juga dimaksudkan untuk dibandingkan kesesuaiannya dengan literatur yang didapat.

Untuk pengolahan data secara fisika dilakukan metode perhitungan dengan rumusan hasilnya angka-angka dan simulasi beberapa soal yang dibuatkan grafiknya.

Berdasarkan sumber wikipedia sifat dari asam sianida diantaranya massa molar : 27,03 $\mathrm{g} / \mathrm{mol}$, penampilan : cairan transparan atau gas tak bewarna, densitas : $0,687 \mathrm{~g} / \mathrm{mL}$, kelarutan dalam air : bercampur, viskositas : $201 \mu \mathrm{Pa}$ s. 


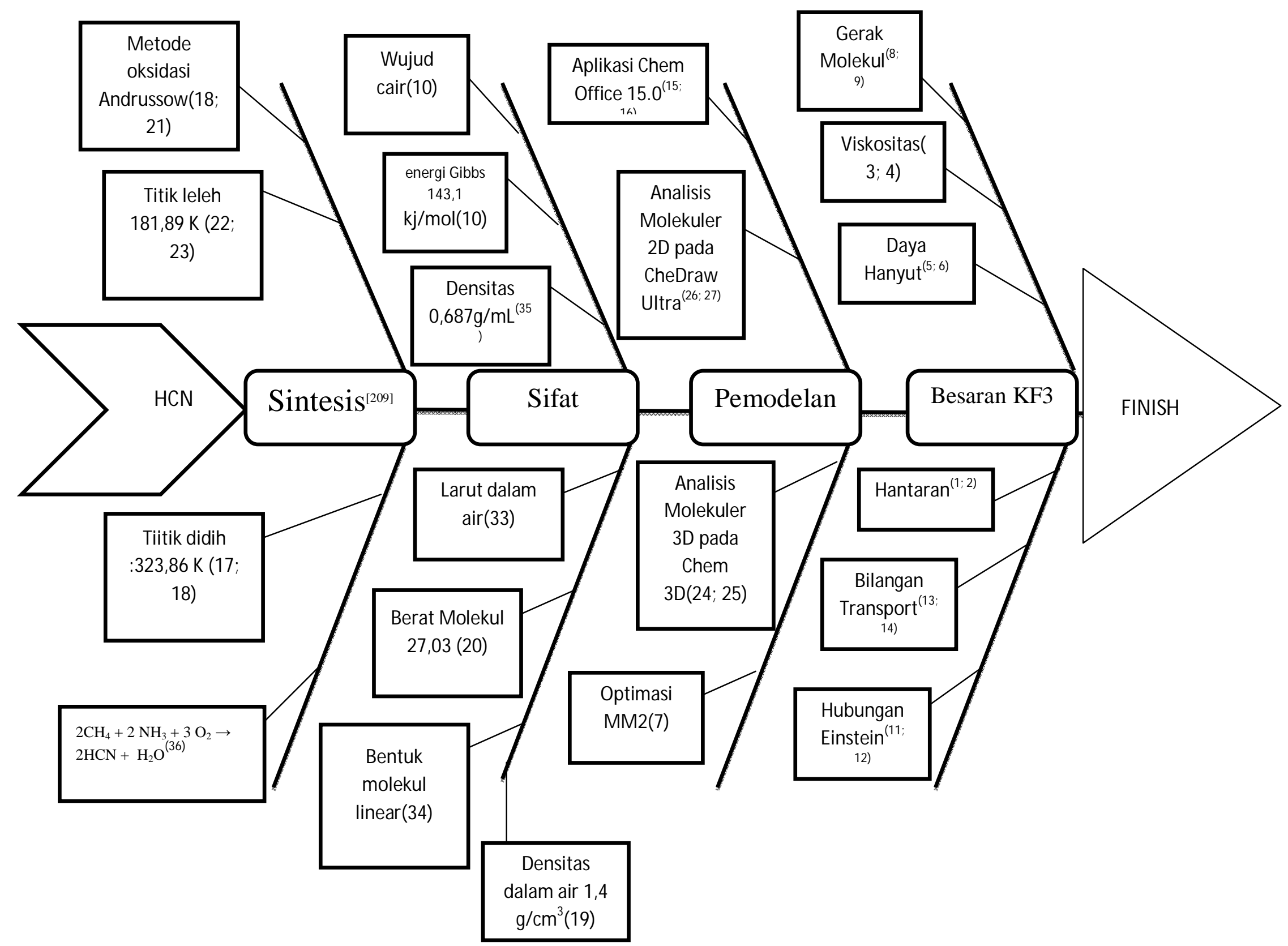




\section{Hasil dan Pembahasan}

\section{Result}

Hidrogen sianida $^{(7 ; 10 ; 26 ; 27 ; 32 ; 46-60)}$ atau biasa disebut formic anammonide, asam hidrosianat, atau asam sianida yang merupakan suatu monobasa dari asam Lewisboron lemah yang dapat digunakan sebagai penyepuhan emas, dan pembuatan pewarna prussian blue (blau), ${ }^{(108)}$. Asam sianida akan larut dalam air ${ }^{(109 ; 110)}$, senyawa ini didalam air akanmembentuk ion $\mathrm{CN}^{-}$dan ion $\mathrm{H}^{+}$.Senyawa dengan rumus kimia $\mathrm{HCN}$ cairan tak bewarna dan sangat beracun. Asam sianida memiliki bentuk molekul ${ }^{(115)}$ linear $^{(116-120)}$ dengan momen dipol ${ }^{(121)} 2.98 \mathrm{D}$.

Tabel 1. Sifat Fisika dan Sifat Kimia Asam Borat https://en.wikipedia.org/wiki/Hydrogen_cyanide

\begin{tabular}{cc}
\hline & Sifat \\
\hline Massa molar & $27.0253 \mathrm{~g} / \mathrm{mol}$ \\
Titik lebur & $-13.29^{\circ} \mathrm{C}\left(8.08^{\circ} \mathrm{F} ; 259.86 \mathrm{~K}\right.$ \\
Titik didih & $26^{\circ} \mathrm{C}\left(79{ }^{\circ} \mathrm{F} ; 299 \mathrm{~K}\right.$ \\
Densitas & $0.6876 \mathrm{~g} \mathrm{~cm}^{-3}$ \\
Keasaman & 9.21 \\
Kebasaan & 4,79 \\
\hline
\end{tabular}

Densitas ${ }^{(94 ;}$ 125; 126) disebut juga dengan kerapatan merupakan massa per satuan volume suatu $\mathrm{zat}^{(211-213)}$ pada suhu ${ }^{(127 ; 128)}$ tertentu dan tidak hanya ditentukan gaya interaksi antar molekul ${ }^{(231-235)}$.Senyawa asam sianida memiliki sifat melarut sempurna pada air, dan sedikit larut dalam etanol. Ada beberapa faktor yang memengaruhi kelarutan suatu senyawa diantaranya sifat dari zat terlarut (solute) ${ }^{(139-143)}$ dan pelarut ${ }^{(144)}$ (solvent) ${ }^{(94 ; 129 ; 132 ; 145 ; 146)}$ dimana zat terlarut yang bersifat polar ${ }^{(214-216)}$ akan mudah larut dalam solvent ${ }^{(243-246)}$ atau yang disebut pelarut yang bersifat polar, begitupun sebaliknya, disini berlaku asas like dissolve like. Suhu, konsentrasi, ${ }^{(95 ;}$ 139; $147-149)$ pengaruh penambahan ion senama ${ }^{(236-237)}$ juga sangat mempengaruhi kelarutan ${ }^{(247-}$ ${ }^{249)}$ suatu senyawa.

\section{Data Molekul HCN}

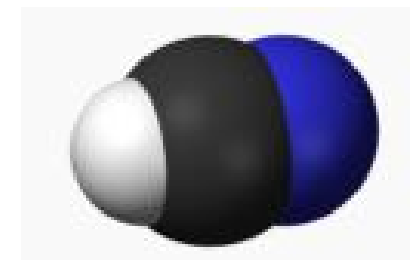

Gambar 2. B(OH) 3 3D

https://id.wikipedia.org/wiki/Hidrogen_sianida

$\begin{array}{ll}\text { Stretch } & : 2.0466 \\ \text { Bend } & : 0.0000 \\ \text { Stretch-Bend } & : 0.0000 \\ \text { Torsion } & : 0.0000 \\ \text { Non-1,4 VDW } & : 0.0000 \\ 1,4 \text { VDW } & : 0.0000 \\ \text { Total Energy } & : 2.0466 \mathrm{kcal} / \mathrm{mol}\end{array}$

Total energy for this frame: $\quad 2.047 \mathrm{kcal} / \mathrm{mol}$ 


\section{Analisa Molekul HCN}

Analisa molekular bertujuan untuk mendapatkan data optimasi, energi dan gambar pada molekul HCN. Untuk memperoleh data pada analisa molekular ini digunakan metode komputasi menggunakan ChemOffice 15.0.

a. Analisa molekul 2D HCN

Pada tahap analisa molekul asam sianida secara 2D digunakan ChemDrawProfessional 15.0.

Dari analisa ini didapatkan gambar dan bentuk molekul seperti berikut:

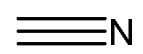

hydrogen cyanide

Gambar 3. HCN 2D ${ }^{(150)}$

$\begin{array}{ll}\text { Chemical Formula } & : \text { CHN } \\ \text { Exact Mass } & : 27,01 \\ \text { Molecular Weight } & : 27,03 \\ \mathrm{~m} / \mathrm{z} & : 27,01(100,0 \%)\end{array}$

Elemental Analysis : C,44,44 H, 3,73 N,51,83

b. Analisa molekul 3D HCN

Analisa molekul HCN menggunakan metode komputasi dibuat dengan software ChemDraw Professional 15.0 kemudian diproyeksikan pada ChemDraw 3D untuk dianalisis struktur tiga dimensinya. Proses ini memperlihatkan kepada kita bagaimana pola pergerakan molekul secara optimal dan bagaimana dinamika interaksi antara $\mathrm{HCN}$ dengan $\mathrm{H}_{2} \mathrm{O}$.

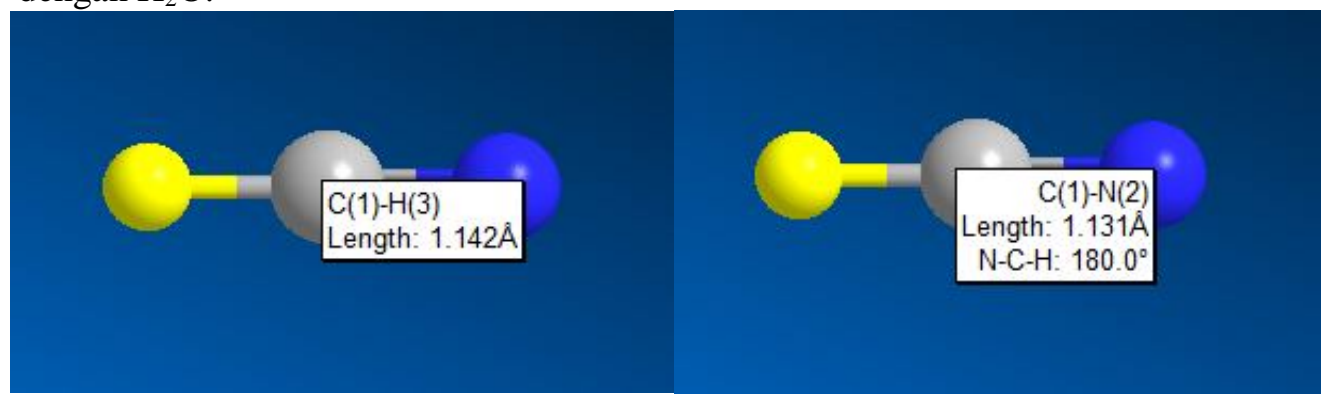

Gambar 3. Analisis 3D pada molekul HCN model Ball and Stick. (a) atom C(1) dan H(3) (b) atom C(1) dan N(2) (Rahmadani,A. ChemOffis 2015)

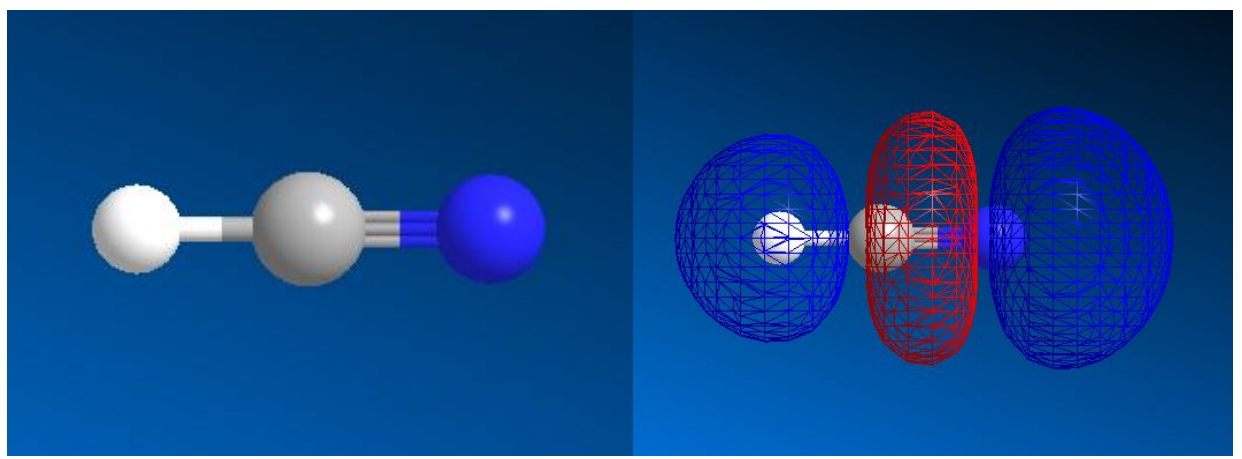

Gambar 4. Analisis 3D pada molekul HCN model Ball and Stick. (a) molekul HCN terdiri dari atom H (bola putih), atom C (bola abu-abu), atom N (bola biru) (b) penampang girasi molekul HCN pada permukaan molekul pada sisi positif (merah) dan pada sisi bermuatan negative (biru) (Rahmadani,A. ChemOffis 2015). 

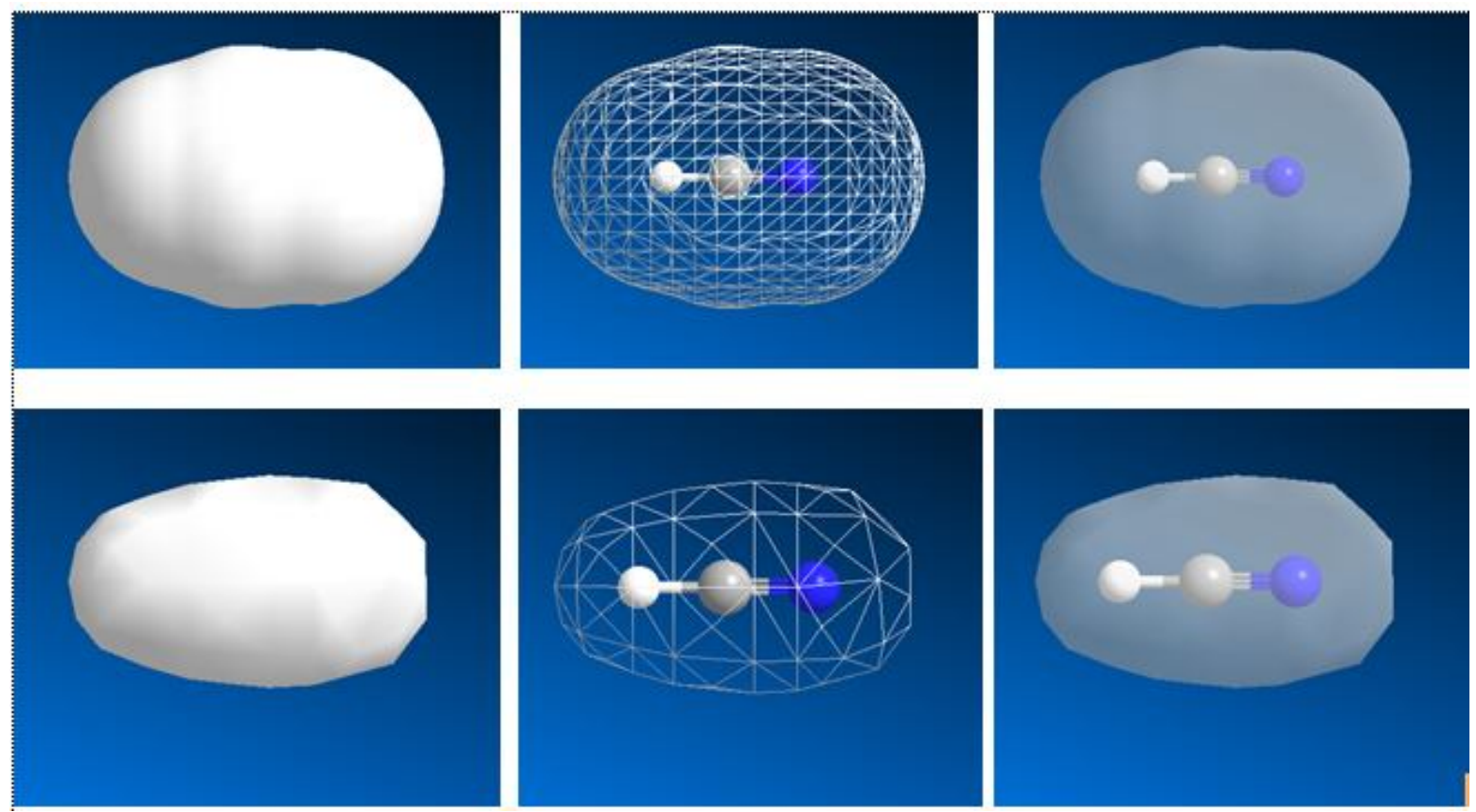

Gambar 5. Analisis 3D Surface HCN. (a) Surface Solvent Accessible molekul HCN,(b) Surface Solvent Accessible molekul HCN Display Mode Wire Mesh (c) Surface Solvent Accessible molekul HCNDisplay Mode Translucent, (d)Surface Connolly Molecular molekul HCN, (e) Surface Connolly Molecular molekul HCNDisplay Mode Wire Mesh,(f) Surface Connolly Molecular molekul HCN Display Mode Translucent.

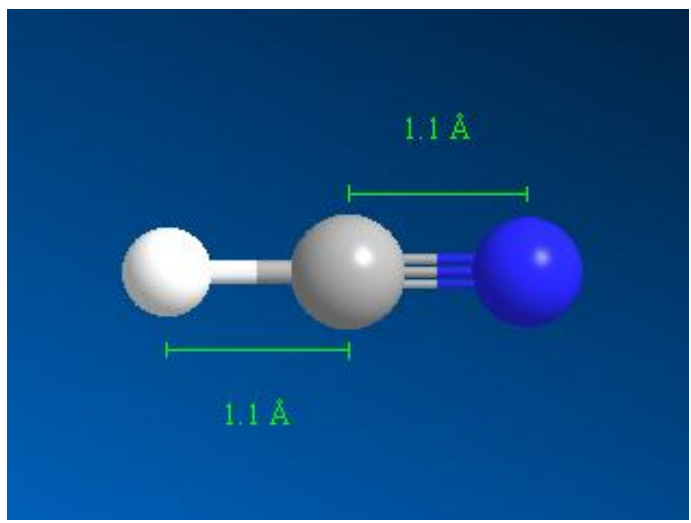

Gambar 6. Jarak antara atom pada molekul HCN dengan menggunakan Measurements Window

\section{Optimasi MM2 pada $\mathrm{HCN}$}

Optimasi molekul HCNdilakukan dengan Molekular ${ }^{[212]}$ Mekanik (MM2) dan menghasilkan output data dalam bentuk data geometri atom atom dalam molekul dan Energi optimumnya. Hasil output yang diperoleh dapat dilihat sebagai berikut :

1. Optimasi MM2 Minimization

2. Optimasi MM2 Dynamics

3. Optimasi MM2 Properties 


\section{Minimize Energy}

$\begin{array}{ll}\text { Stretch } & : 2.0466 \\ \text { Bend } & : 0.0000 \\ \text { Stretch-Bend } & : 0.0000 \\ \text { Torsion } & : 0.0000 \\ \text { Non-1,4 VDW } & : 0.0000 \\ 1,4 \text { VDW } & : 0.0000 \\ \text { Total Energy } & : 2.0466 \mathrm{kcal} / \mathrm{mol}\end{array}$

Total energy for this frame: $2.047 \mathrm{kcal} / \mathrm{mol}$

\section{1) Analisa MM2 dynamics pada $\mathrm{HCN}$}

Translational Kinetic Energy: 0.0000 Rotational Kinetic Energy: 0.3165

2) Analisa MM2 Properties HCN

$\begin{array}{llc}\text { Stretch } & : & 2.0466 \\ \text { Bend } & : & 0.0000 \\ \text { Stretch-Bend } & : & 0.0000 \\ \text { Torsion } & : & 0.0000 \\ \text { Non-1,4 VDW } & : & 0.0000 \\ 1,4 \text { VDW } & : & 0.0000 \\ \text { Total Energy } & : & 2.0466 \mathrm{kcal} / \mathrm{mol}\end{array}$

The total energy for this frame $\quad: \quad 2.047 \mathrm{kcal} / \mathrm{mol}$

Dari hasil optimasi MM2 terhadap molekul menggunakan metode komputasi diperoleh energi stretch molekul HCN sebesar 2,0466 energy bend, torsion, dan 1,4 VDW masingmasing 0,0000 sehingga total energi keseluruhan adalah 2,047 kcal/mol.

\section{Jari-Jari Atom Penyusun HCN}

Asam sianida ${ }^{(1-40)}$ adalah senyawa kimia yang mengandung gugus siano $\mathrm{C} \equiv \mathrm{N}$ yang terikat dengan atom hidrogen ${ }^{(7 ; 10 ; 26 ; 27 ; 32 ; 41-45)}$, atom karbon terikat tiga ke atom nitrogen. Pada gugus $\mathrm{CN}$ sebagai ion sianida poliatomik yang bermuatan negatif $\left(\mathrm{CN}^{-}\right)$. Hidrogen Sianida salah satu senyawa yang sangat beracun. Anion $\mathrm{CN}$ - bersifat isoelektronik jika berikatan dengan molekul nitrogen dan karbon monoksida.

$\mathrm{HCN}$ terdiri atas tiga atom penyusun yaitu atom $\mathrm{H}, \mathrm{C}$,dan $\mathrm{N}$, jari-jari ketiga atom ini memiliki perbedaan jari-jari. Jari-jari atom merupakan jarak antara inti ke elektron terluar atom di suatu atom. Perbedaan jari-hari ini dapat dilihat dari tabel diabawah ini :

Tabel 2. Jari-jari atom $\mathrm{H}, \mathrm{B}$, dan $\mathrm{O}$

https://id.wikipedia.org/wiki/Jari-jari_atom

\begin{tabular}{clcccc}
\hline Simbol & Nama & \multicolumn{4}{c}{ Jari-jari $(\mathrm{pm})$} \\
\cline { 3 - 6 } & & Empiris & $\begin{array}{c}\text { Hasil } \\
\text { Perhitungan }\end{array}$ & $\begin{array}{c}\text { Van der } \\
\text { Waals }\end{array}$ & Kovalen \\
H & Hidrogen & 25 & 53 & 120 & 37 \\
$\mathbf{C}$ & Carbon & 70 & 67 & 170 & 77 \\
$\mathbf{N}$ & Nitrogen & 60 & 56 & 155 & 75 \\
\hline
\end{tabular}


Jari -jari molekul merupakan jarak antara satu atom ke atom lainnya dalam susunan tertentu yang terikat secara bersama melalui sebuah ikatan kimia.

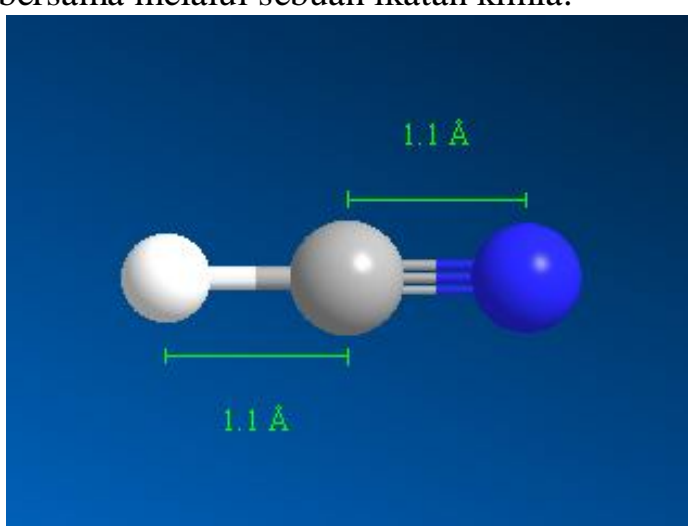

Gambar 6. Jarak antara atom pada molekul HCN dengan menggunakan Measurements Window

Pada fasa ${ }^{(151)}$ liquid asam sianida terdiri atas lapisan ${ }^{(152)}$ molekul HCN yang terikat bersama dengan ikatan hidrogen ${ }^{(153)}$ ( seperti gambar ) Dimana panjang ikatan H-C 1,1 amstrong dan $\mathrm{C}$ dengan $\mathrm{N} \mathrm{1,1} \mathrm{amstrong} \mathrm{.}$

\section{Sifat Termodinamika}

Keadaan termodinamika ${ }^{(155)}$ merupakan keadaan secara makroskopik ${ }^{(72 ; 73 ; 156)}$ dari suatu sistem dimana sifat-sifatnya hanya sebatas percobaan menggunakan peralatan laboratorium yang menjaga sifat-sifat tersebut pada nilai tertentu yang dipilih dan keadaannya tidak bergantung pada waktu.

Berdasarkan percobaan didapatkan sifat termodinamika asam borat sebagai berikut:

\begin{tabular}{ll}
\hline & \multicolumn{1}{c}{ Termodinamika } \\
\hline$\frac{\text { Kapasitas }}{\text { kalor }(C)}$ & $71,00 /(\mathrm{mol} \cdot \mathrm{K})$ \\
$\frac{\text { Entropi molar }}{\underline{\text { standar }}\left(S^{\ominus}\right)}$ & $113,01 \mathrm{~J} /(\mathrm{mol} \cdot \mathrm{K})$ \\
$\frac{\text { Entalpi }}{\text { pembentukan }}$ & $109,9 \mathrm{~kJ} / \mathrm{mol}$ \\
$\underline{\underline{\text { standar }}\left(\Delta_{\mathrm{f}} H^{\ominus}\right)}$ & \\
$\frac{\text { Energi bebas }}{\text { Gibbs }\left(\Delta_{\mathrm{f}} G\right)}$ & $143,1 \mathrm{kj} / \mathrm{mol}$ \\
\hline
\end{tabular}

pembuatan asam sianida $(\mathrm{HCN})$ yang paling sering dilakukan menggunakan metode, yang diciptakan oleh Leonid Andrussow, dimana metana ${ }^{(155-174)}$, dan amonia bereaksi pada suhu ${ }^{[206]}$ sekitar $1200^{\circ} \mathrm{C}$ menggunakan katalis platina ${ }^{(175-194)}$, dengan reaksi sebagai berikut :

$2 \mathrm{CH}_{4}+2 \mathrm{NH}_{3}+3 \mathrm{O}_{2} \rightarrow 2 \mathrm{HCN}+\mathrm{H}_{2} \mathrm{O}$ 
Energi yang dibutuhkan untuk reaksi ini berasal dari panas yang timbul akibat reaksi oksidasi parsial metana dan amonia.

Proses pembuatan HCN lainnya adalah proses Degussa (BMA proses) dimana tidak ada oksigen ditambahkan dan energi harus ditransfer secara tidak langsung melalui dinding reaktor, dengan reaksi sebagai berikut :

$\mathrm{CH}_{4}+\mathrm{NH}_{3} \rightarrow \mathrm{HCN}+3 \mathrm{H}_{2}$

Asam hidrosianat (HCN) juga bisa diekstrak dar daun, bunga, atau umbi-umbian dari tanaman beracun yan memiliki cyanohydrins, dengan cara hidrolisis yang diikuti proses pengasaman dan penyulingan.

Harga $\Delta \mathrm{H}_{\mathrm{f}}^{\mathrm{o}} \mathrm{komponenya} \mathrm{pada} \mathrm{suhu} 298 \mathrm{~K}$ dapat dilihat pada tabel 5. dibawah ini:

Tabel 4. Harga $\Delta \mathrm{H}_{\mathrm{f} 298}^{\mathrm{o}}$ Masing-masing Komponen ${ }^{(157)}$

\begin{tabular}{cc}
\hline Komponen & $\Delta \mathbf{H}_{\mathbf{f}}^{\mathbf{0}} \mathbf{2 9 8}(\mathbf{k J} / \mathbf{~ m o l})$ \\
\hline $\mathbf{C H}_{\mathbf{4}}$ & $-74,9$ \\
$\mathbf{N H}_{\mathbf{3}}$ & $-46,3$ \\
$\mathbf{H C N}$ & -20 \\
$\mathbf{H}_{\mathbf{2}}$ & 0 \\
\hline
\end{tabular}

$$
\begin{aligned}
\Delta \mathrm{H}_{\mathrm{R}}^{\mathrm{o}} & \left.=\Delta \mathrm{H}_{\mathrm{f} \text { produk }}^{\mathrm{o}}-\Delta \mathrm{H}_{\mathrm{f} \text { reaktan }}^{\mathrm{o}}+3 \mathrm{x} \quad \Delta \mathrm{H}_{\mathrm{f}}^{\mathrm{o}}, \quad \mathrm{H}_{2}\right)-\left(\Delta \mathrm{H}_{\mathrm{f}}^{\mathrm{o}} \mathrm{CH}_{4}+\Delta \mathrm{H}_{\mathrm{f}}^{\mathrm{o}}\right. \\
& =\quad\left(\Delta \mathrm{H}_{\mathrm{f}}^{\mathrm{o}}, \quad \mathrm{HCN}+\mathrm{NH}_{3}\right) \\
& =((-20)+(3 \mathrm{x} 0))-((-74,9)+(-46,3)) \mathrm{kJ} / \mathrm{mol}) \\
& =-141,2 \mathrm{~kJ} / \mathrm{mol}
\end{aligned}
$$

\section{Gerakan ion}

Sebelum menentukan pengukuran konduktivitas,terlebih dahulu mengetahui penyebab dari pergerakan ion dengan laju yang berbeda-beda, dan penyebab ion tersebut memiliki konduktivitas molar yang berlainan,serta sebab konduktivitas molar ${ }^{(166)}$ elektrolit kuat berkurang dengan akar konsentrasi. ${ }^{(167)}$

Konsep nya adalah makin besar mobilitas ion ${ }^{(168 ; 169)}$ dalam larutan, ${ }^{(134)}$ maka semakin besar pula kontribusinya pada konduktivitas (untuk muatan tertentu).

\begin{tabular}{cc}
\multicolumn{2}{c}{ Tabel 5.Mobilitas Ionik dalam Air pada suhu $298 \mathrm{~K}^{(157)}$} \\
\hline Ion & Mobilitas ionik $\left(\mathbf{1 0}^{-8} \mathbf{m}^{2} \mathbf{s}^{-1} \mathbf{V}^{-1}\right)$ \\
\hline $\mathbf{K}^{+}$ & 7,62 \\
$\mathbf{N a}^{+}$ & 5,19 \\
$\mathbf{C l}^{-}$ & 7,91 \\
$\mathbf{N O 3}^{-}$ & 7,40 \\
$\mathbf{F}^{-}$ & 5,70 \\
\hline
\end{tabular}

Terdapat beberapa faktor yang mempengaruhi kecepatan ion diantaranya:

1. Muatan ion, dimana ion bergerak semakin cepat karena muatan ion semakin ringan.

2. Terdapat hidrasi, semakin sedikit molekul air yang melingkupi ion semakin cepat pergerakan ion.

3. Gaya tarik antar ion, dimana gaya tarik besar gerakan ion akan melambat.

4. Temperatur, dimana temperatur tinggi ${ }^{(170)}$ maka kecepatan ion akan meningkat.

\section{Viskositas}

Viskositas merupakan suatu ukuran ketahanan dari fluida yang dipengaruhi oleh tekanan maupun tegangan. Viskositas larutan encer $\mathrm{HCN}$ dengan komposisi yang khas dari pendingin 
reaktor daya air ${ }^{(171)}$ ringan telah diukur untuk tiga komposisi boron antara 1500 ppm(berat) dan 3500 ppm pada rentang suhu $30^{\circ} \mathrm{C}-60^{\circ} \mathrm{C}$ menggunakan viskometer Cannon-Ubbelohde yang dikalibrasi. Viskositas larutan encer ini mengikuti persamaan Arrhenius dari bentuk (persamaan) dimana vc adalah viskositas kinematik $\left(\mathrm{m}^{2} / \mathrm{s}\right)$ dari larutan $\mathrm{HCN}$.

\section{Kecepatan hanyut}

Jika dua elektroda ${ }^{(172-176)}$ yang terpisah dengan jarak $\mathrm{l}$ berada pada selisih potensial $\Delta \phi$, maka ion dalam larutan diantara kedua elektroda ${ }^{(177)}$ itu,mengalami medan listrik ${ }^{(178-182)}$ seragam, seperti:

$$
\mathrm{E}=\frac{\Delta \emptyset}{\mathrm{l}}
$$

Untuk ion (muatan ion) mengalami gaya sebesar :

$$
\mathrm{F}=\mathrm{zeE}=\frac{\mathrm{ze} \emptyset \emptyset}{\mathrm{l}}
$$

Kation $^{(97 ; 173 ; 183-185)}$ bereaksi dengan percepatan menuju elektroda $^{(186)}$ negatif dan anion ${ }^{(97 ;}$ 149; 183; 187; 188) bereaksi dengan percepatan menuju elektroda positif. Akan tetapi,saat ion bergerak melalui pelarut ${ }^{(189-191)}$ maka ion akan mengalami gaya gesekan ${ }^{(192-196)}$ memperlambat muatan ${ }^{(197)}$ yang setara dengan kecepatannya.dan jika dianalogikan hukumStokes ${ }^{(198-202)}$ untuk bola radius ${ }^{(179 ; 203-206)}$ a dan s berlaku pada skala mikroskopis, maka kita dapat menuliskan gaya perlambatan $^{(207-211)}$ ini dibawah ini:

$$
\mathrm{F}^{\prime}=\mathrm{fs} \quad \mathrm{f}=6 \pi \eta \alpha
$$

Kedua gaya itu bekerja dalam arah yang berlawanan,dan ion mencapai kecepatan akhir,yaitu kecepatan hanyut, ${ }^{(212-216)}$ jika gaya mempercepat Ie diimbangi oleh penahan kentalle'.Gaya neto menjadi nol (Ie = Ie' ), jika:

Dimana:

$$
\begin{aligned}
& S=\frac{z e E}{f} \\
& U=\frac{x}{t\left(\frac{d E}{d x}\right)}
\end{aligned}
$$

$\mathrm{x}=\operatorname{jarak}(\mathrm{m})$

$\mathrm{t}=$ waktu $(\mathrm{dt})$

$\left(\frac{\mathbf{d E}}{\mathbf{d x}}\right)=$ kekuatan medan $\left(\right.$ volt. $\left.\mathrm{m}^{-1}\right)$

$$
\mathrm{E}=\frac{\mathrm{dE}}{\mathrm{dx}}
$$

Maka,

$\mathrm{Z}=$ valensi kation

$$
\mathrm{U}=\frac{\lambda_{\mathrm{m}}}{\mathrm{zF}}
$$

$\mathrm{F}=$ Faraday

Karena adanya kecepatan hanyut ${ }^{(217)}$ yang mengatur laju transportasi ion, sehingga diharapkan konduktivitas akan berkurang seiring bertambahnya viskositas pelarut akan ukuran ion.

Perhitungan kecepatan hanyut :

Misalkan potensial $\mathrm{HCN}$ 3,50 V dan jarak antar elektroda adalah 1,5 cm, maka kecepatan hanyutnya dapat dihitung sebagai berikut :

$\mathrm{E}=\frac{\Delta \emptyset}{1}$

$\mathrm{E}=\frac{3.50 \mathrm{~V}}{1,5 \mathrm{~cm}}=2,33 \mathrm{~V} / \mathrm{cm}$

Jadi kecepatan hanyut HCNadalah 2,33 V/ cm

\section{Konduktiviti}

Konduktiviti merupakan suatu ukuran kemampuan suatu senyawa dalam menghantarkan listrik. ${ }^{(218)}$ Berdasarkan penelitian, pengukuran konduktivitas listrik ${ }^{(219)}$ dari larutan asam sianida 
$\left(15-110 \mathrm{~g} / \mathrm{kg}-\mathrm{H}_{2} \mathrm{O}=0,251-1,815 \mathrm{~mol} / \mathrm{kg}-\mathrm{H}_{2} 0\right)$ dapat diukur dalam rentang suhu 25 sampai $75^{\circ} \mathrm{C}$ ${ }^{(167)}$ pada tekanan uap jenuh dalam sel kaca menggunakan elektroda platinum konsentris. Konduktansi spesifik dari $\mathrm{HCN}_{3(\mathrm{aq})}$ dapat dihitung setelah koreksi untuk konduktansi pelarut(air) dan ditabulasikan.Konduktivitas suatu larutan dapat dipengaruhi oleh besarnya konsentrasi larutan tersebut. Semakin tinggi konsentrasi maka semakin tinggi pula konduktivitasnya. Untuk mengetahui pengaruh konsentrasi terhadap konduktivitas maka dapat dianalogikan sebagai berikut:

Suatu larutan X 0,1\% ditimbang 0,1 gram, lalu dilarutkan dalam labu ukur $100 \mathrm{ml}$ kemudian dilakukan penambahan air sampai tanda batas. Lalu larutan diencerkan menjadi $0,08 \%, 0,06 \%, 0,04 \%$ dan $0,02 \%$ dan diukur menggunakan konduktimeter sehingga diperoleh data sebagai berikut.

Tabel 6. Hasil pengukuran konduktivitas larutan X

\begin{tabular}{cc}
\hline Konsentrasi $(\%)$ & Konduktivitas $(\mathrm{mS} / \mathrm{cm})$ \\
\hline $\mathbf{0 , 1}$ & 2,45 \\
$\mathbf{0 , 0 8}$ & 1,75 \\
$\mathbf{0 , 0 6}$ & 1,25 \\
$\mathbf{0 , 0 4}$ & 0,82 \\
$\mathbf{0 , 0 2}$ & 0,50 \\
\hline
\end{tabular}

Dari data diatas dapat diasumsikan bahwa konduktivitas larutan $\mathrm{X}$ meningkat seiring bertambahnya konsentrasi larutan. Konsentrasi berbanding lurus dengan konduktivitas. Sehingga dari data didapatkan grafik sebagai berikut:

Grafik 1. Pengaruh Konsentrasi Terhadap Konduktivitas

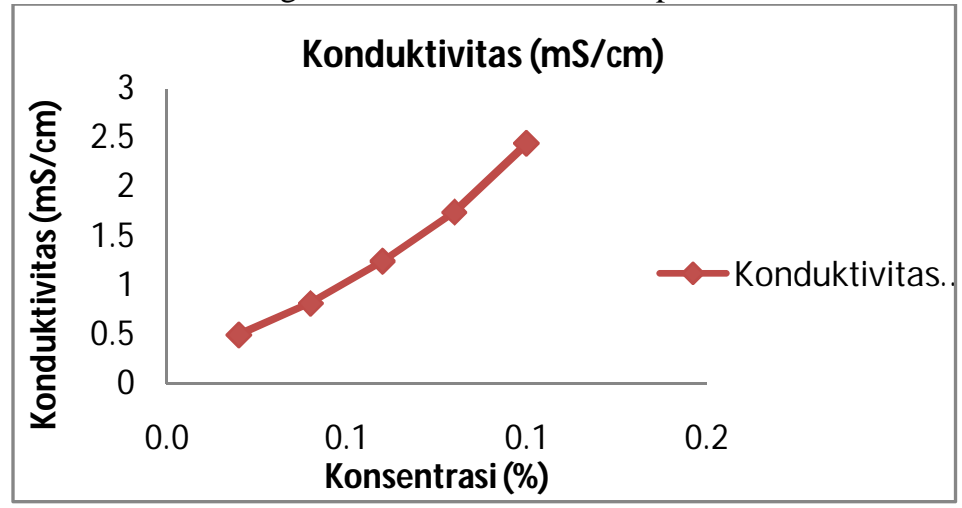

Selain menggunakan konduktimeter, konduktivitas bisa ditentukan melalui rumus berikut:

$$
\mathrm{K}=1 \mathrm{P}(\Omega-1 \mathrm{~cm}-1)
$$

Konduktivitas biasanya terdapat dalam $\mathrm{mScm}^{-1}$ dan konsentrasi M. Sehingga hubungannya diketahui dalam mho/cm seperti:

$$
\begin{aligned}
& \mathrm{R}=\mathrm{p} \times 1 \mathrm{~A} \\
& \mathrm{k}=1 \mathrm{RA} \\
& \mathrm{Am}=\frac{100 \times \frac{\mathrm{K}}{\left(\mathrm{scm}^{-1}\right)} \mathrm{cm}^{2} \mathrm{~mol}^{-1}}{\mathrm{C} / \mathrm{M}}
\end{aligned}
$$

\section{Besaran Kimia Fisika 3}

a. Bilangan Transport

Fraksi dari arus total ${ }^{(220-224)}$ yang dibawa oleh ion jenis tertentu. Untuk larutan dengan dua jenis ion, bilangan transport kation :

$$
t_{+}=\frac{I^{+}}{I}
$$


$\mathrm{I}=$ arus total

$$
I=t_{+}+t_{-}
$$

Bilangan transport pembatas $\left(\mathrm{t}^{0}\right)$ untuk limit konsentrasi nol dari larutan elektrolit. ${ }^{(47 ;}$ 225-229)

Jika $I \propto \kappa$ sehingga :

$$
t^{0}=\frac{z v u}{\sum_{i} z v u_{i}}
$$

Untuk elektrolit simetris (bilangan muatan untuk kedua ion sama) maka persamaan diatas disederhanakan :

$$
t^{0}=\frac{u}{\sum_{i} u_{i}}
$$

Hubungan antara konduktivitas ion dengan mobilitas ion ${ }^{(188 ; 230-234)}$ :

$$
t^{0}=\frac{v \lambda}{\sum_{i} v_{i} \lambda_{i}}=\frac{v \lambda}{\Lambda_{m}^{0}}
$$

Jadi untuk setiap jenis ion :

$$
v \lambda=t^{0} \Lambda_{m}^{0}
$$

\section{a. Hukum Pertama Fick Tentang Difusi}

Andaikan fluks pertikel yang berdifusi, merupakan gerakan sebagai reaksi terhadap gaya termodinamika yang timbul dari gradient konsentrasi ${ }^{[270-273]}$. Partikel ${ }^{[266-269]}$ akan mencapai kecepatan hanyut tetap $s$ jika gaya termodinamika $f$ sama dengan tahan kental.kecepatan hanyut ini sebanding dengan gaya termodinamika, dan kita tuliskan $s \propto f$. Akan tetapi, fluks partikel $J$ sebanding dengan kecepatan hanyut, dan gaya termodinamika sebanding dengan gradient konsentrasidc $/ d x$.

Rantai kesebandingan itu $(J \propto s, s \propto £$, dan $f \propto d c / d x$ menunjukkan bahwa:

$$
J \propto \frac{d c}{d x}
$$

\section{b. Hubungan Einstein} waktu adalah:

Hukum Fick untuk fluks partikel dalam mol molekul ${ }^{(227)}$ per satuan luas per satuan

$$
\mathrm{J}=-\mathrm{D} \frac{d c}{d x}
$$

Dengan D merupakan koefisien difusi dan $d c / d x$ merupakan kemiringan dari konsentrasi molar.

Fluks partikel berhubungan dengan kec epatan hanyut, dengan:

$$
J=s c
$$

\section{c. Energy Stability}

Energi stabilitas yaitu stabilitas termodinamik dari sistem kimia, ${ }^{(251)}$ dimana energi ${ }^{(75)}$ yang terjadi ketika sebuah sistem berada dalam keadaan energi terendah atau kesetimbangan kimia dengan lingkungannya. Energy stabiliy dari molekul ${ }^{(252)}$ asam sianida yang diperoleh dari data aplikasi ChemDraw 3D dapat dilihat sebagai berikut: 
Analisa MM2 dynamics pada $\mathrm{HCN}$

MM2 Calculation completed successfully

-MM2 Dynamics

Warning: Some parameters are guessed (Quality $=1)$.

Iteration Time Total Energy Potential Energy Temperature

$\begin{array}{ccccc}\text { 2. } & 0.024 & 0.048 \pm 0.000 & 0.038 \pm 0.000 & 1.05 \pm 0.00 \\ \text { 3. } & 0.026 & 0.082 \pm 0.000 & 0.045 \pm 0.000 & 4.18 \pm 0.00 \\ \text { 4. } & 0.028 & 0.089 \pm 0.000 & 0.016 \pm 0.000 & 8.08 \pm 0.00 \\ \text { 5. } & 0.030 & 0.093 \pm 0.000 & 0.091 \pm 0.000 & 0.18 \pm 0.00\end{array}$

Translational Kinetic Energy: 0.0000 Rotational Kinetic Energy: 0.0000

Translational Kinetic Energy: 0.0000 Rotational Kinetic Energy: : 2.047 kcal/mol Calculation ended

\section{IV.Kesimpulan}

Hidrogen Sianida larut dalam air. Hidrogen sianida bersifat toxic atau beracun. Analisis energi kinetik rotasi senyawa pada Chemdraw 2D 2,0466 kcal/mol Analisis jari-jari atom hidrogen dengan carbon pada Chemdraw 3D didapatkan sebesar 1,1 A, dan jari jari atom carbon dengan nitrogen masing-masingnya sebesar 1,1 A. Data yang didapat pada Analisa MM2 dynamics HCN adalah interaction time $0.024,0.026,0.028,0.030$, total energy $0.048,0.082$, potensial energy 0.38 , $0.045,0.016,0.091$. Sifat termodinamika hidrogen sianida adalah entropi $(\Delta \mathrm{S}) 113,01 \mathrm{~J} / \mathrm{kmol}$, entalpi pembentukan standar $\left(\Delta_{\mathrm{f}} \mathrm{H}\right)-141,2 \mathrm{~kJ} / \mathrm{mol}$, entalpi pembakaran standar $\left(\Delta_{\mathrm{c}} \mathrm{H}\right)-426,5 \mathrm{~kJ} / \mathrm{mol}$ dan kecepatan hanyut yang didapat berdasarkan perhitungan sebesar $2,33 \mathrm{~V} / \mathrm{cmsifat}$ dari asam sianida diantaranya massa molar : 27,03 $\mathrm{g} / \mathrm{mol}$, penampilan : cairan transparan atau gas tak bewarna, densitas : $0,687 \mathrm{~g} / \mathrm{mL}$, kelarutan dalam air : bercampur, viskositas : $201 \mu \mathrm{Pa}$ s. Kegunaan hidrogen sianida dalam bidang industri pembuatan emas dan perak, kemudian pembuatan warna prussian blue (pewarna blau). 


\section{Referensi :}

1. Asahara H, Sofue A, Kuroda Y, Nishiwaki N. 2018. Alkynylation and Cyanation of Alkenes Using Diverse Properties of a Nitro Group. The Journal of organic chemistry

2. Beauparlant P, Bedard D, Bernier C, Chan H, Gilbert K, et al. 2009. Preclinical development of the nicotinamide phosphoribosyl transferase inhibitor prodrug GMX1777. Anti-cancer drugs 20:346-54

3. Betancourt-Buitrago LA, Ossa-Echeverry OE, Rodriguez-Vallejo JC, Barraza JM, Marriaga N, Machuca-Martinez F. 2018. Anoxic photocatalytic treatment of synthetic mining wastewater using $\mathrm{TiO} 2$ and scavengers for complexed cyanide recovery. Photochemical \& photobiological sciences : Official journal of the European Photochemistry Association and the European Society for Photobiology

4. Bidwai AK, Ahrendt AJ, Sullivan JS, Vitello LB, Erman JE. 2015. pH dependence of cyanide and imidazole binding to the heme domains of Sinorhizobium meliloti and Bradyrhizobium japonicum FixL. Journal of inorganic biochemistry 153:88-102

5. Cerna D, Li H, Flaherty S, Takebe N, Coleman CN, Yoo SS. 2012. Inhibition of nicotinamide phosphoribosyltransferase (NAMPT) activity by small molecule GMX1778 regulates reactive oxygen species (ROS)-mediated cytotoxicity in a p53- and nicotinic acid phosphoribosyltransferase1 (NAPRT1)-dependent manner. The Journal of biological chemistry 287:22408-17

6. Chen D, Xu MH. 2014. Lewis acid promoted diastereoselective addition of TMSCN and TMSCF3 to isatin-derived N-sulfinyl ketimines: synthesis of optically active tetrasubstituted 3-aminooxindoles. The Journal of organic chemistry 79:7746-51

7. Darabi Mahboub MJ, Dubois JL, Cavani F, Rostamizadeh M, Patience GS. 2018. Catalysis for the synthesis of methacrylic acid and methyl methacrylate. Chemical Society reviews 47:7703-38

8. Eiserich JP, Ott SP, Kadir T, Morrissey BM, Hayakawa KA, et al. 2018. Quantitative assessment of cyanide in cystic fibrosis sputum and its oxidative catabolism by hypochlorous acid. Free radical biology \& medicine 129:146-54

9. Emandi G, Flanagan KJ, Senge MO. 2018. Fluorescent imidazole-based chemosensors for the reversible detection of cyanide and mercury ions. Photochemical \& photobiological sciences : Official journal of the European Photochemistry Association and the European Society for Photobiology 17:1450-61

10. Felestrino EB, Vieira IT, Caneschi WL, Cordeiro IF, Assis RAB, et al. 2018. Biotechnological potential of plant growth-promoting bacteria from the roots and rhizospheres of endemic plants in ironstone vegetation in southeastern Brazil. World journal of microbiology \& biotechnology 34:156

11. Ferus M, Civis S, Mladek A, Sponer J, Juha L, Sponer JE. 2012. On the road from formamide ices to nucleobases: IR-spectroscopic observation of a direct reaction between cyano radicals and formamide in a high-energy impact event. Journal of the American Chemical Society 134:20788-96

12. Fujii S, Hayashi H, Itoh K, Yamada S, Deguchi Y, Kawazu K. 2013. Characterization of the carrier-mediated transport of ketoprofen, a nonsteroidal anti-inflammatory drug, in rabbit corneal epithelium cells. The Journal of pharmacy and pharmacology 65:171-80 
13. Gandhi M, Rajagopal D, Parthasarathy S, Raja S, Huang ST, Senthil Kumar A. 2018. In Situ Immobilized Sesamol-Quinone/Carbon Nanoblack-Based Electrochemical Redox Platform for Efficient Bioelectrocatalytic and Immunosensor Applications. ACS omega 3:10823-35

14. Gunther J, Irmisch S, Lackus ND, Reichelt M, Gershenzon J, Kollner TG. 2018. The nitrilase PtNIT1 catabolizes herbivore-induced nitriles in Populus trichocarpa. BMC plant biology $18: 251$

15. Jentsch NG, Hume JD, Crull EB, Beauti SM, Pham AH, et al. 2018. Quinolines from the cyclocondensation of isatoic anhydride with ethyl acetoacetate: preparation of ethyl 4hydroxy-2-methylquinoline-3-carboxylate and derivatives. Beilstein journal of organic chemistry 14:2529-36

16. Katono M, Bessho T, Meng S, Humphry-Baker R, Rothenberger G, et al. 2011. D-pi-A dye system containing cyano-benzoic acid as anchoring group for dye-sensitized solar cells. Langmuir : the ACS journal of surfaces and colloids 27:14248-52

17. Kimura O, Tsukagoshi K, Endo T. 2008. Uptake of 4-chloro-2-methylphenoxyacetic acid (MCPA) from the apical membrane of Caco- 2 cells by the monocarboxylic acid transporter. Toxicology and applied pharmacology 227:325-30

18. Lamsabhi AM, Mo O, Yanez M, Guillemin JC, Haldys V, et al. 2008. Ni(+) reactions with aminoacetonitrile, a potential prebiological precursor of glycine. Journal of mass spectrometry : JMS 43:317-26

19. Lim HK, Chen J, Sensenhauser C, Cook K, Preston R, et al. 2011. Overcoming the genotoxicity of a pyrrolidine substituted arylindenopyrimidine as a potent dual adenosine $\mathrm{A}(2 \mathrm{~A}) / \mathrm{A}(1)$ antagonist by minimizing bioactivation to an iminium ion reactive intermediate. Chemical research in toxicology 24:1012-30

20. Lohar S, Dhara K, Roy P, Sinha Babu SP, Chattopadhyay P. 2018. Highly Sensitive Ratiometric Chemosensor and Biomarker for Cyanide Ions in the Aqueous Medium. ACS omega 3:10145-53

21. Lucas HR, Karlin KD. 2009. Copper-Carbon Bonds in Mechanistic and Structural Probing of Proteins as well as in Situations where Copper is a Catalytic or Receptor Site. Metal ions in life sciences 6:295-361

22. Luque-Almagro VM, Merchan F, Blasco R, Igeno MI, Martinez-Luque M, et al. 2011. Cyanide degradation by Pseudomonas pseudoalcaligenes CECT5344 involves a malate:quinone oxidoreductase and an associated cyanide-insensitive electron transfer chain. Microbiology 157:739-46

23. Mito MS, Silva AA, Kagami FL, Dario de Almeida J, Mantovanelli GC, et al. 2018. Responses of the weed species Bidens pilosa L. to exogenous application of the steroidal saponin protodioscin and the plant growth regulators 24-epibrassinolide, indol-3-acetic acid and abscisic acid. Plant biology

24. Nakazawa M, Ando H, Nishimoto A, Ohta T, Sakamoto K, et al. 2018. Anaerobic Respiration Coupled with Mitochondrial Fatty Acid Synthesis in Wax Ester Fermentation by Euglena gracilis. FEBS letters

25. Puentes-Cala E, Harder J. 2018. An RND transporter in the monoterpene metabolism of Castellaniella defragrans. Biodegradation

26. Ralser M. 2018. An appeal to magic? The discovery of a non-enzymatic metabolism and its role in the origins of life. The Biochemical journal 475:2577-92

27. Shalayel I, Coulibaly S, Ly KD, Milet A, Vallee Y. 2018. The Reaction of Aminonitriles with Aminothiols: A Way to Thiol-Containing Peptides and Nitrogen Heterocycles in the Primitive Earth Ocean. Life 8

28. Sosa-Torres ME, Kroneck PM. 2009. Interaction of cyanide with enzymes containing vanadium, manganese, non-heme iron, and zinc. Metal ions in life sciences 6:363-93

29. Sudar M, Vasic-Racki D, Muller M, Walter A, Blazevic ZF. 2018. Mathematical model of the MenD-catalyzed 1,4-addition (Stetter reaction) of alpha-ketoglutaric acid to acrylonitrile. Journal of biotechnology 268:71-80

30. Szczepanik B, Styrcz S. 2011. Protolytic dissociation of cyanophenols in ground and excited states in alcohol and water solutions. Spectrochimica acta. Part A, Molecular and biomolecular spectroscopy 79:451-5 
31. Szczepanik B, Styrcz S, Gora M. 2008. Protolytic dissociation of cyanoanilines in the ground and excited state in water and methanol solutions. Spectrochimica acta. Part A, Molecular and biomolecular spectroscopy 71:403-9

32. Takishita Y, Charron JB, Smith DL. 2018. Biocontrol Rhizobacterium Pseudomonas sp. 23S Induces Systemic Resistance in Tomato (Solanum lycopersicum L.) Against Bacterial Canker Clavibacter michiganensis subsp. michiganensis. Frontiers in microbiology 9:2119

33. Tarleton M, Gilbert J, Sakoff JA, McCluskey A. 2012. Cytotoxic 2-phenyacrylnitriles, the importance of the cyanide moiety and discovery of potent broad spectrum cytotoxic agents. European journal of medicinal chemistry 57:65-73

34. Umekawa Y, Ito K. 2018. Thioredoxin o-mediated reduction of mitochondrial alternative oxidase in the thermogenic skunk cabbage Symplocarpus renifolius. Journal of biochemistry

35. Urbancsok J, Bones AM, Kissen R. 2018. Benzyl Cyanide Leads to Auxin-Like Effects Through the Action of Nitrilases in Arabidopsis thaliana. Frontiers in plant science 9:1240

36. Watson M, Roulston A, Belec L, Billot X, Marcellus R, et al. 2009. The small molecule GMX1778 is a potent inhibitor of NAD+ biosynthesis: strategy for enhanced therapy in nicotinic acid phosphoribosyltransferase 1-deficient tumors. Molecular and cellular biology 29:5872-88

37. Wu CW, Kang CH, Lin YF, Tung KL, Deng YH, et al. 2016. Towards Acid-Tolerated Ethanol Dehydration: Chitosan-Based Mixed Matrix Membranes Containing Cyano-Bridged Coordination Polymer Nanoparticles. Journal of nanoscience and nanotechnology 16:4141-6

38. Yau WW, Singh BK, Lesmana R, Zhou J, Sinha RA, et al. 2018. Thyroid hormone (T3) stimulates brown adipose tissue activation via mitochondrial biogenesis and MTOR-mediated mitophagy. Autophagy:1-20

39. Yilmaz O, Oderinde MS, Emmert MH. 2018. Photoredox-Catalyzed Calpha-H Cyanation of Unactivated Secondary and Tertiary Aliphatic Amines: Late-Stage Functionalization and Mechanistic Studies. The Journal of organic chemistry 83:11089-100

40. Zabka TS, Singh J, Dhawan P, Liederer BM, Oeh J, et al. 2015. Retinal toxicity, in vivo and in vitro, associated with inhibition of nicotinamide phosphoribosyltransferase. Toxicological sciences : an official journal of the Society of Toxicology 144:163-72

41. Haumann M, Stripp ST. 2018. The Molecular Proceedings of Biological Hydrogen Turnover. Accounts of chemical research 51:1755-63

42. Kuzmanovic N, Eltlbany N, Ding G, Baklawa M, Min L, et al. 2018. Analysis of the genome sequence of plant beneficial strain Pseudomonas sp. RU47. Journal of biotechnology 281:183-92

43. Li SL, Yen JH, Kano K, Liu SM, Liu CL, et al. 2018. Using metabolic charge production in the tricarboxylic acid cycle (QTCA) to evaluate the extracellular-electron-transfer performances of Shewanella spp. Bioelectrochemistry 124:119-26

44. Petkovic AM, Jakovljevic VL, Bradic JV, Jeremic JN, Jeremic NS, et al. 2018. The Effects of Potassium Cyanide on the Functional Recovery of Isolated Rat Hearts after Ischemia and Reperfusion: The Role of Oxidative Stress. Oxidative medicine and cellular longevity 2018:5979721

45. Tagele SB, Kim SW, Lee HG, Kim HS, Lee YS. 2018. Effectiveness of multi-trait Burkholderia contaminans KNU17BI1 in growth promotion and management of banded leaf and sheath blight in maize seedling. Microbiological research 214:8-18

46. Santangelo JS, Thompson KA, Johnson MTJ. 2018. Herbivores and plant defenses affect selection on plant reproductive traits more strongly than pollinators. Journal of evolutionary biology

47. Hansen CIC, Sorensen M, Veiga TAM, Zibrandtsen JFS, Heskes AM, et al. 2018. Reconfigured cyanogenic glucoside biosynthesis in Eucalyptus cladocalyx involves a cytochrome P450 CYP706C55. Plant physiology

48. Thodberg S, Del Cueto J, Mazzeo R, Pavan S, Lotti C, et al. 2018. Elucidation of the Amygdalin Pathway Reveals the Metabolic Basis of Bitter and Sweet Almonds (Prunus dulcis). Plant physiology 
49. Go MR, Kim HJ, Yu J, Choi SJ. 2018. Toxicity and Toxicokinetics of Amygdalin in Maesil ( Prunus mume) Syrup: Protective Effect of Maesil against Amygdalin Toxicity. Journal of agricultural and food chemistry

50. Ernouf G, Wilt I, Zahim S, Wuest WM. 2018. Epoxy isonitriles, a unique class of antibiotics Synthesis of their metabolites and biological investigations. Chembiochem : a European journal of chemical biology

51. Sirisena D, Perera NCN, Godahewa GI, Kwon H, Yang H, et al. 2018. A manganese superoxide dismutase (MnSOD) from red lip mullet, Liza haematocheila: Evaluation of molecular structure, immune response, and antioxidant function. Fish \& shellfish immunology 84:73-82

52. Ziegler EW, Kim HJ, Benner SA. 2018. Molybdenum(VI)-Catalyzed Rearrangement of Prebiotic Carbohydrates in Formamide, a Candidate Prebiotic Solvent. Astrobiology 18:115970

53. Staugler JM, Babin MC, Matthews MC, Brittain MK, Perry MR. 2018. Development of a hydrogen cyanide inhalation exposure system and determination of the inhaled median lethal dose in the swine model. Inhalation toxicology 30:195-202

54. Wang G, Peng Z, Peng S, Qiu J, Li Y, Lan Y. 2018. (E)-N-Aryl-2-oxo-2-(3,4,5trimethoxyphenyl)acetohydrazonoyl cyanides as tubulin polymerization inhibitors: Structurebased bioisosterism design, synthesis, biological evaluation, molecular docking and in silico ADME prediction. Bioorganic \& medicinal chemistry letters 28:3350-5

55. Nouri Moghadam F, Amirnasr M, Meghdadi S, Eskandari K, Buchholz A, Plass W. 2019. A new fluorene derived Schiff-base as a dual selective fluorescent probe for $\mathrm{Cu}(2+)$ and $\mathrm{CN}()$. Spectrochimica acta. Part A, Molecular and biomolecular spectroscopy 207:6-15

56. Ennis C, Auchettl R, Appadoo DRT, Robertson EG. 2018. The prediction of far-infrared spectra for planetary nitrile ices using periodic density functional theory with comparison to thin film experiments. Physical chemistry chemical physics : PCCP 20:23593-605

57. Saeed O, Boyer NL, Pamplin JC, Driscoll IR, DellaVolpe J, et al. 2018. Inhalation Injury and Toxic Industrial Chemical Exposure. Military medicine 183:130-2

58. Fan X, Jiang J, Zhang X, Liu K, Wang S, et al. 2018. Self-marked HCN gas based FBG demodulation in thermal cycling process for aerospace environment. Optics express 26:22944-53

59. Audi SH, Friedly N, Dash RK, Beyer AM, Clough AV, Jacobs ER. 2018. Detection of hydrogen peroxide production in the isolated rat lung using Amplex red. Free radical research:1-11

60. Chen Y, Hu X, Rao C, Li Z, Chen L, et al. 2018. A reusable cyanide sensor via activation of $\mathrm{C}-\mathrm{H}$ group: trifluoromethylcarbinol-directed meta-C-H cyanomethylation of naphthalimide. The Analyst 143:4655-61

61. Barnard IRM, Tierney P, Campbell CL, McMillan L, Moseley H, et al. 2018. Quantifying Direct DNA Damage in the Basal Layer of Skin Exposed to UV Radiation from Sunbeds. Photochemistry and photobiology 94:1017-25

62. Chan B, Easton CJ, Radom L. 2018. Effect of Hydrogen Bonding and Partial Deprotonation on the Oxidation of Peptides. The journal of physical chemistry. A 122:1741-6

63. Cummings M, Arumanayagam ACS, Zhao P, Kannanganat S, Stuve O, et al. 2018. Presenilin1 regulates Th1 and Th17 effector responses but is not required for experimental autoimmune encephalomyelitis. PloS one 13:e0200752

64. Eagen WJ, Baumoel LR, Osman SH, Rahlwes KC, Morita YS. 2018. Deletion of PimE mannosyltransferase results in increased copper sensitivity in Mycobacterium smegmatis. FEMS microbiology letters 365

65. Eapen A, Sparks A. 2018. Improved outcomes following frozen embryo transfer does not provide a "universal license to chill". Fertility and sterility 110:847-8

66. Easterling CP, Kubo T, Orr ZM, Fanucci GE, Sumerlin BS. 2017. Synthetic upcycling of polyacrylates through organocatalyzed post-polymerization modification. Chemical science 8:7705-9 
67. Eastham ND, Logsdon JL, Manley EF, Aldrich TJ, Leonardi MJ, et al. 2018. Hole-Transfer Dependence on Blend Morphology and Energy Level Alignment in Polymer: ITIC

Photovoltaic Materials. Advanced materials 30

68. Eastlack RK, Ledesma JB, Tran S, Khalsa A, Park P, et al. 2018. Home Versus

Rehabilitation: Factors that Influence Disposition After Minimally Invasive Surgery in Adult Spinal Deformity Surgery. World neurosurgery 118:e610-e5

69. ElAfandy RT, Ebaid M, Min JW, Zhao C, Ng TK, Ooi BS. 2018. Flexible InGaN nanowire membranes for enhanced solar water splitting. Optics express 26:A640-A50

70. Greene NT, Alhussaini MA, Easter JR, Argo TFt, Walilko T, Tollin DJ. 2018. Intracochlear pressure measurements during acoustic shock wave exposure. Hearing research 365:149-64

71. Hamuro Y, E SY. 2018. Determination of Backbone Amide Hydrogen Exchange Rates of Cytochrome c Using Partially Scrambled Electron Transfer Dissociation Data. Journal of the American Society for Mass Spectrometry 29:989-1001

72. Joglekar P, Sonnenburg ED, Higginbottom SK, Earle KA, Morland C, et al. 2018. Genetic Variation of the SusC/SusD Homologs from a Polysaccharide Utilization Locus Underlies Divergent Fructan Specificities and Functional Adaptation in Bacteroides thetaiotaomicron Strains. mSphere 3

73. Kirchner JE, Landes SJ, Eagan AE. 2017. Applying KT Network Complexity to a HighlyPartnered Knowledge Transfer Effort Comment on "Using Complexity and Network Concepts to Inform Healthcare Knowledge Translation". International journal of health policy and management 7:560-2

74. Laschuk NO, Ebralidze, II, Poisson J, Egan JG, Quaranta S, et al. 2018. Ligand Impact on Monolayer Electrochromic Material Properties. ACS applied materials \& interfaces

75. Liptak C, Mahmoud MM, Eckenroth BE, Moreno MV, East K, et al. 2018. I260Q DNA polymerase beta highlights precatalytic conformational rearrangements critical for fidelity. Nucleic acids research

76. Ngom M, Imren S, Maetzig T, Adair JE, Knapp D, et al. 2018. UM171 Enhances Lentiviral Gene Transfer and Recovery of Primitive Human Hematopoietic Cells. Molecular therapy. Methods \& clinical development 10:156-64

77. Nnamani NS, Pugh MJ, Amuan ME, Eapen BC, Hudak SJ, et al. 2018. Outcomes of Genitourinary Injury in U.S. Iraq and Afghanistan War Veterans Receiving Care from the Veterans Health Administration. Military medicine

78. Perocheau DP, Cunningham S, Lee J, Antinao Diaz J, Waddington SN, et al. 2018. AgeRelated Seroprevalence of Antibodies Against AAV-LK03 in a UK Population Cohort. Human gene therapy

79. Phan TD, Eastwood JP, Shay MA, Drake JF, Sonnerup BUO, et al. 2018. Electron magnetic reconnection without ion coupling in Earth's turbulent magnetosheath. Nature 557:202-6

80. Shimauchi T, Caucheteux S, Finsterbusch K, Turpin J, Blanchet F, et al. 2018. Dendritic Cells Promote the Spread of Human T-Cell Leukemia Virus Type 1 via Bidirectional Interactions with CD4(+) T Cells. The Journal of investigative dermatology

81. Shivley CB, Lombard JE, Urie NJ, Haines DM, Sargent R, et al. 2018. Preweaned heifer management on US dairy operations: Part II. Factors associated with colostrum quality and passive transfer status of dairy heifer calves. Journal of dairy science 101:9185-98

82. Surlis C, Earley B, McGee M, Keogh K, Cormican P, et al. 2018. Blood immune transcriptome analysis of artificially fed dairy calves and naturally suckled beef calves from birth to 7 days of age. Scientific reports 8:15461

83. Thien K, Bowtell M, Eaton S, Bardell-Williams M, Downey L, et al. 2018. Clozapine use in early psychosis. Schizophrenia research 199:374-9

84. Todd CG, McGee M, Tiernan K, Crosson P, O'Riordan E, et al. 2018. An observational study on passive immunity in Irish suckler beef and dairy calves: Tests for failure of passive transfer of immunity and associations with health and performance. Preventive veterinary medicine 159:182-95

85. Trotter Ii RT, Camplain R, Eaves ER, Fofanov VY, Dmitrieva NO, et al. 2018. Health Disparities and Converging Epidemics in Jail Populations: Protocol for a Mixed-Methods Study. JMIR research protocols 7:e10337 
86. Urie NJ, Lombard JE, Shivley CB, Kopral CA, Adams AE, et al. 2018. Preweaned heifer management on US dairy operations: Part I. Descriptive characteristics of preweaned heifer raising practices. Journal of dairy science 101:9168-84

87. Vailes MT, McCoski SR, Wooldridge LK, Reese ST, Pohler KG, et al. 2019. Post-transfer outcomes in cultured bovine embryos supplemented with epidermal growth factor, fibroblast growth factor 2, and insulin-like growth factor 1. Theriogenology 124:1-8

88. Xie X, Earle FS, Myers EB. 2018. Sleep Facilitates Generalisation of Accent Adaptation to a New Talker. Language, cognition and neuroscience 33:196-210

89. Yuan Z, Benck JD, Eatmon Y, Blankschtein D, Strano MS. 2018. Stable, TemperatureDependent Gas Mixture Permeation and Separation through Suspended Nanoporous SingleLayer Graphene Membranes. Nano letters 18:5057-69

90. Zou Y, Duan X, Xue Z, E M, Sun M, et al. 2018. Water use conflict between wetland and agriculture. Journal of environmental management 224:140-6

91. Alphonse RS, Vadivel A, Coltan L, Eaton F, Barr AJ, et al. 2011. Activation of Akt protects alveoli from neonatal oxygen-induced lung injury. American journal of respiratory cell and molecular biology 44:146-54

92. Antonyuk SV, Han C, Eady RR, Hasnain SS. 2013. Structures of protein-protein complexes involved in electron transfer. Nature 496:123-6

93. Balla J, Vercellotti GM, Nath K, Yachie A, Nagy E, et al. 2003. Haem, haem oxygenase and ferritin in vascular endothelial cell injury. Nephrology, dialysis, transplantation : official publication of the European Dialysis and Transplant Association - European Renal Association 18 Suppl 5:v8-12

94. Barlow CK, Wright A, Easton CJ, O'Hair RA. 2011. Gas-phase ion-molecule reactions using regioselectively generated radical cations to model oxidative damage and probe radical sites in peptides. Organic \& biomolecular chemistry 9:3733-45

95. Earnhardt JN, Qian M, Tu C, Laipis PJ, Silverman DN. 1998. Intramolecular proton transfer from multiple sites in catalysis by murine carbonic anhydrase V. Biochemistry 37:7649-55

96. Earnhardt JN, Wright SK, Qian M, Tu C, Laipis PJ, et al. 1999. Introduction of histidine analogs leads to enhanced proton transfer in carbonic anhydrase V. Archives of biochemistry and biophysics 361:264-70

97. Hicks KA, O'Leary SE, Begley TP, Ealick SE. 2013. Structural and mechanistic studies of $\mathrm{HpxO}$, a novel flavin adenine dinucleotide-dependent urate oxidase from Klebsiella pneumoniae. Biochemistry 52:477-87

98. Morris CJ, Earl JR, Trenam CW, Blake DR. 1995. Reactive oxygen species and iron--a dangerous partnership in inflammation. The international journal of biochemistry \& cell biology 27:109-22

99. New K, Flint A, Bogossian F, East C, Davies MW. 2012. Transferring preterm infants from incubators to open cots at $1600 \mathrm{~g}$ : a multicentre randomised controlled trial. Archives of disease in childhood. Fetal and neonatal edition 97:F88-92

100. Ong KC, Ng AW, Lee LS, Kaw G, Kwek SK, et al. 2004. Pulmonary function and exercise capacity in survivors of severe acute respiratory syndrome. The European respiratory journal 24:436-42

101. Peterson DA, Eaton JW. 1989. Electron transfer facilitated by superoxide dismutase: a model for membrane redox systems? Biochemical and biophysical research communications 165:164-7

102. Rey-Parra GJ, Archer SL, Bland RD, Albertine KH, Carlton DP, et al. 2008. Blunted hypoxic pulmonary vasoconstriction in experimental neonatal chronic lung disease. American journal of respiratory and critical care medicine 178:399-406

103. Sutton AD, Bailey M, Bellomo R, Eastwood GM, Pilcher DV. 2014. The association between early arterial oxygenation in the ICU and mortality following cardiac surgery. Anaesthesia and intensive care 42:730-5

104. Thornburg JM, Nelson KK, Clem BF, Lane AN, Arumugam S, et al. 2008. Targeting aspartate aminotransferase in breast cancer. Breast cancer research : BCR 10:R84

105. Tran TH, Krishnamoorthy K, Begley TP, Ealick SE. 2011. A novel mechanism of sulfur transfer catalyzed by O-acetylhomoserine sulfhydrylase in the methionine-biosynthetic 
pathway of Wolinella succinogenes. Acta crystallographica. Section D, Biological crystallography 67:831-8

106. Tu C, Qian M, Earnhardt JN, Laipis PJ, Silverman DN. 1998. Properties of intramolecular proton transfer in carbonic anhydrase III. Biophysical journal 74:3182-9

107. Vadivel A, Alphonse RS, Etches N, van Haaften T, Collins JJ, et al. 2014. Hypoxia-inducible factors promote alveolar development and regeneration. American journal of respiratory cell and molecular biology 50:96-105

108. Vora RA, Pegg AE, Ealick SE. 1998. A new model for how O6-methylguanine-DNA methyltransferase binds DNA. Proteins 32:3-6

109. Bellomo R, Bailey M, Eastwood GM, Nichol A, Pilcher D, et al. 2011. Arterial hyperoxia and in-hospital mortality after resuscitation from cardiac arrest. Critical care 15:R90

110. Cushen JD, Otsuka I, Bates CM, Halila S, Fort S, et al. 2012. Oligosaccharide/siliconcontaining block copolymers with $5 \mathrm{~nm}$ features for lithographic applications. ACS nano 6:3424-33

111. Lakshmi KV, Eaton SS, Eaton GR, Brudvig GW. 1999. Orientation of the tetranuclear manganese cluster and tyrosine $\mathrm{Z}$ in the $\mathrm{O}(2)$-evolving complex of photosystem II: An EPR study of the $\mathrm{S}(2) \mathrm{Y}(\mathrm{Z})(*)$ state in oriented acetate-inhibited photosystem II membranes. Biochemistry 38:12758-67

112. Mohammadnejad S, Ataei A, Nabi Bidhendi GR, Mehrdadi N, Ebadati F, Lotfi F. 2012. Water pinch analysis for water and wastewater minimization in Tehran oil refinery considering three contaminants. Environmental monitoring and assessment 184:2709-28

113. Skarsgard LD, Henkelman RM, Eaves CJ. 1980. Pions for radiotherapy at TRIUMF. Journal of the Canadian Association of Radiologists 31:3-12

114. Swoboda S, Castro JA, Earsing KA, Lipsett PA. 1997. Road trips and resources: there is a better way. Critical care 1:105-10

115. Watts ZI, Easton CJ. 2009. Peculiar stability of amino acids and peptides from a radical perspective. Journal of the American Chemical Society 131:11323-5

116. Kim J, Lee SW, Kim MH, Park OO. 2018. Zigzag-Shaped Silver Nanoplates: Synthesis via Ostwald Ripening and Their Application in Highly Sensitive Strain Sensors. ACS applied materials \& interfaces

117. Helbig KL, Lauerer RJ, Bahr JC, Souza IA, Myers CT, et al. 2018. De Novo Pathogenic Variants in CACNA1E Cause Developmental and Epileptic Encephalopathy with Contractures, Macrocephaly, and Dyskinesias. American journal of human genetics

118. Sarode S, Upadhyay P, Khosa MA, Mak T, Shakir A, et al. 2018. Overview of wastewater treatment methods with special focus on biopolymer chitin-chitosan. International journal of biological macromolecules

119. Stark H. 2018. Artificial Chemotaxis of Self-Phoretic Active Colloids: Collective Behavior. Accounts of chemical research

120. Kasner EJ, Fenske RA, Hoheisel GA, Galvin K, Blanco MN, et al. 2018. Spray Drift from a Conventional Axial Fan Airblast Sprayer in a Modern Orchard Work Environment. Annals of work exposures and health

121. Zhang Z, Zhang Q, Xiao Q, Sun H, Gao H, et al. 2018. Distribution of runs of homozygosity in Chinese and Western pig breeds evaluated by reduced-representation sequencing data. Animal genetics

122. Ishiuchi SI, Sasaki Y, Lisy JM, Fujii M. 2018. Ion-peptide interactions between alkali metal ions and a termini-protected dipeptide: modeling a portion of the selectivity filter in $\mathrm{K}(+)$ channels. Physical chemistry chemical physics : PCCP

123. Gadzuk-Shea MM, Bush MF. 2018. Effects of Charge State on the Structures of Serum Albumin Ions in the Gas Phase: Insights from Cation-to-Anion Proton-Transfer Reactions, Ion Mobility, and Mass Spectrometry. The journal of physical chemistry. $B$

124. Pandey J, Shrivastava V, Nagarajan R. 2018. Metastable Bi2Zr2O7 with Pyrochlore-like Structure: Stabilization, Oxygen Ion Conductivity, and Catalytic Properties. Inorganic chemistry 
125. Blackburn DG, Lestz L, Barnes MS, Powers KG, Langkilde T. 2018. Morphological features of the yolk processing pattern in the eastern fence lizard, Sceloporus undulatus (Phrynosomatidae). Journal of morphology

126. Shklyaev OE, Shum H, Balazs AC. 2018. Using Chemical Pumps and Motors To Design Flows for Directed Particle Assembly. Accounts of chemical research

127. Liang YJ, Yang WX. 2018. Kinesins in MAPK cascade: How kinesin motors are involved in the MAPK pathway? Gene

128. Akanuma Y, Kuzuya T, Hayashi M, Ide T, Kuzuya N. 1970. Immunological reactivity of insulin to sepharose coupled with insulin-antibody---its use for the extraction of insulin from serum. Biochemical and biophysical research communications 38:947-53

129. Bhuiyan AI, Papajani VT, Paci M, Melino S. 2015. Glutathione-garlic sulfur conjugates: slow hydrogen sulfide releasing agents for therapeutic applications. Molecules 20:1731-50

130. Cotting J, Zysset T, Reichen J. 1989. Biliary obstruction dissipates bioelectric sinusoidalcanalicular barrier without altering taurocholate uptake. The American journal of physiology 256:G312-8

131. Fonnum F. 1969. Radiochemical micro assays for the determination of choline acetyltransferase and acetylcholinesterase activities. The Biochemical journal 115:465-72

132. Giebultowicz J, Ruzycka M, Fudalej M, Krajewski P, Wroczynski P. 2016. LC-MS/MS method development and validation for quantitative analyses of 2-aminothiazoline-4carboxylic acid--a new cyanide exposure marker in post mortem blood. Talanta 150:586-92

133. Haddad NI, Yuan Q. 2005. Purification and some properties of $\mathrm{Cu}, \mathrm{Zn}$ superoxide dismutase from Radix lethospermi seed, kind of Chinese traditional medicine. Journal of chromatography. B, Analytical technologies in the biomedical and life sciences 818:123-31

134. Hicks DB, Krulwich TA. 1990. Purification and reconstitution of the F1F0-ATP synthase from alkaliphilic Bacillus firmus OF4. Evidence that the enzyme translocates $\mathrm{H}+$ but not $\mathrm{Na}+$. The Journal of biological chemistry 265:20547-54

135. Hlavica P, Aichinger G. 1978. Studies on the cytochrome P-450 product complexes formed during the metabolism of N,N-dimethylaniline. Biochimica et biophysica acta 544:185-99

136. Houeto P, Buneaux F, Galliot-Guilley M, Baud FJ, Levillain P. 1994. Determination of hydroxocobalamin and cyanocobalamin by derivative spectrophotometry in cyanide poisoning. Journal of analytical toxicology 18:154-8

137. Jermak S, Pranaityte B, Padarauskas A. 2007. Ligand displacement, headspace single-drop microextraction, and capillary electrophoresis for the determination of weak acid dissociable cyanide. Journal of chromatography. A 1148:123-7

138. Julak J. 2005. Chromatographic analysis in bacteriologic diagnostics of blood cultures, exudates, and bronchoalveolar lavages. Prague medical report 106:175-94

139. Lachenmeier DW, Schehl B, Kuballa T, Frank W, Senn T. 2005. Retrospective trends and current status of ethyl carbamate in German stone-fruit spirits. Food additives and contaminants 22:397-405

140. Liebman SA, Pesce-Rodriguez RA, Matthews CN. 1995. Organic analysis of hydrogen cyanide polymers: prebiotic and extraterrestrial chemistry. Advances in space research : the official journal of the Committee on Space Research 15:71-80

141. Liu C, DeGrandpre Y, Porter A, Griffiths A, McAdam K, et al. 2011. The use of a novel tobacco treatment process to reduce toxicant yields in cigarette smoke. Food and chemical toxicology : an international journal published for the British Industrial Biological Research Association 49:1904-17

142. Lutai AV, Marakushkin LA, Kolesov VG. 1974. [Hygienic evaluation of working conditions and state of health of the workers of the cyanide process stage at the gold extraction plants]. Gigiena truda i professional'nye zabolevaniia 18:31-3

143. Madhavan ND, Naidu KA. 2000. Purification and partial characterization of peroxidase from human term placenta of non-smokers: metabolism of benzo(a)pyrene-7, 8-dihydrodiol. Placenta 21:501-9

144. Mitoraj MP, Parafiniuk M, Srebro M, Handzlik M, Buczek A, Michalak A. 2011. Applications of the ETS-NOCV method in descriptions of chemical reactions. Journal of molecular modeling 17:2337-52 
145. Montgomery HA, Gardiner DK, Gregory JG. 1969. Determination of free hydrogen cyanide in river water by a solvent-extraction method. The Analyst 94:284-91

146. Motaghed M, Mousavi SM, Rastegar SO, Shojaosadati SA. 2014. Platinum and rhenium extraction from a spent refinery catalyst using Bacillus megaterium as a cyanogenic bacterium: statistical modeling and process optimization. Bioresource technology 171:401-9

147. Neiss WF. 1984. Electron staining of the cell surface coat by osmium-low ferrocyanide. Histochemistry 80:231-42

148. Schoeneberger H, Gross R, Cremer HD, Elmadfa I. 1982. Composition and protein quality of Lupinus mutabilis. The Journal of nutrition 112:70-6

149. Seto Y. 1995. Oxidative conversion of thiocyanate to cyanide by oxyhemoglobin during acid denaturation. Archives of biochemistry and biophysics 321:245-54

150. Shekarchizadeh H, Ensafi AA, Kadivar M. 2013. Selective determination of sucrose based on electropolymerized molecularly imprinted polymer modified multiwall carbon nanotubes/glassy carbon electrode. Materials science \& engineering. C, Materials for biological applications 33:3553-61

151. Shemansky DE, Stewart AI, West RA, Esposito LW, Hallett JT, Liu X. 2005. The Cassini UVIS stellar probe of the Titan atmosphere. Science 308:978-82

152. Tsuge K, Kataoka M, Seto Y. 2001. Rapid determination of cyanide and azide in beverages by microdiffusion spectrophotometric method. Journal of analytical toxicology 25:228-36

153. Zhang Z, Sun X, Wang L, Liu H, Lu Q. 1997. [Comparison of two extraction methods for maxingshigan decoction]. Zhongguo Zhong yao za $z$ hi $=$ Zhongguo zhongyao zazhi $=$ China journal of Chinese materia medica 22:413-5, 47

154. Aleksic Z, Jankovic S, Dimitrijevic B, Divnic-Resnik T, Milinkovic I, Lekovic V. 2010. [The use of platelet-rich fibrin membrane in gingival recession treatment]. Srpski arhiv za celokupno lekarstvo 138:11-8

155. Carvalho L, Monteiro R, Figueira P, Mieiro C, Pereira E, et al. 2018. Rare earth elements in mud volcano sediments from the Gulf of Cadiz, South Iberian Peninsula. The Science of the total environment 652:869-79

156. Dandu NK, Adeyiga O, Panthi D, Bird SA, Odoh SO. 2018. Performance of density functional theory for describing hetero-metallic active-site motifs for methane-to-methanol conversion in metal-exchanged zeolites. Journal of computational chemistry

157. Fu L, Bai YN, Lu YZ, Ding J, Zhou D, Zeng RJ. 2018. Degradation of organic pollutants by anaerobic methane-oxidizing microorganisms using methyl orange as example. Journal of hazardous materials 364:264-71

158. Ghosh P, Shah G, Chandra R, Sahota S, Kumar H, et al. 2018. Assessment of methane emissions and energy recovery potential from the municipal solid waste landfills of Delhi, India. Bioresource technology

159. Hong J, Li M, Zhang J, Sun B, Mo F. 2018. C-H Bond Carboxylation with Carbon Dioxide. ChemSusChem

160. Kozlova EA, Lyulyukin MN, Markovskaya DV, Selishchev DS, Cherepanova SV, Kozlov DV. 2018. Synthesis of Cd1-xZnxS photocatalysts for gas-phase CO2 reduction under visible light. Photochemical \& photobiological sciences : Official journal of the European Photochemistry Association and the European Society for Photobiology

161. Kruger C, Lisitsin-Baranovsky E, Ofer O, Turgeon PA, Vermette J, et al. 2018. A magnetically focused molecular beam source for deposition of spin-polarised molecular surface layers. The Journal of chemical physics 149:164201

162. Kurade MB, Saha S, Salama ES, Patil SM, Govindwar SP, Jeon BH. 2018. Acetoclastic methanogenesis led by Methanosarcina in anaerobic co-digestion of fats, oil and grease for enhanced production of methane. Bioresource technology 272:351-9

163. Liu Y, Chen J, Song J, Hai Z, Lu X, et al. 2018. Adjusting the rheological properties of cornstraw slurry to reduce the agitation power consumption in anaerobic digestion. Bioresource technology 272:360-9

164. Loizia P, Neofytou N, Zorpas AA. 2018. The concept of circular economy strategy in food waste management for the optimization of energy production through anaerobic digestion. Environmental science and pollution research international 
165. Marquart KA, Haller BR, Paper JM, Flynn TM, Boyanov MI, et al. 2018. Influence of pH on the balance between methanogenesis and iron reduction. Geobiology

166. Meng Y, Jiang Z, Li N, Zhao Z, Cheng T, et al. 2018. Protective Effects of Methane-Rich Saline on Renal Ischemic-Reperfusion Injury in a Mouse Model. Medical science monitor : international medical journal of experimental and clinical research 24:7794-801

167. Moges ME, Todt D, Janka E, Heistad A, Bakke R. 2018. Sludge blanket anaerobic baffled reactor for source-separated blackwater treatment. Water science and technology : a journal of the International Association on Water Pollution Research 78:1249-59

168. Mokomele T, da Costa Sousa L, Balan V, van Rensburg E, Dale BE, Gorgens JF. 2018. Incorporating anaerobic co-digestion of steam exploded or ammonia fiber expansion pretreated sugarcane residues with manure into a sugarcane-based bioenergy-livestock nexus. Bioresource technology 272:326-36

169. Schimmelmann A, Fernandez-Cortes A, Cuezva S, Streil T, Lennon JT. 2018. Radiolysis via radioactivity is not responsible for rapid methane oxidation in subterranean air. PloS one 13:e0206506

170. Vandenbrande S, Waroquier M, Van Speybroeck V, Verstraelen T. 2018. Ab initio evaluation of Henry coefficients using importance sampling. Journal of chemical theory and computation

171. Witze A. 2018. Mars scientists edge closer to solving methane mystery. Nature 563:18-9

172. Ye M, Misra SK, De AK, Ostadhossein F, Singh K, et al. 2018. Design, Synthesis and Characterization of Globular Orphan Nuclear Receptor Regulator with Biological Activity in Soft Tissue Sarcoma. Journal of medicinal chemistry

173. Yun J, Jung H, Choi H, Oh KC, Jeon JM, et al. 2018. Performance evaluation of an on-site biocomplex textile as an alternative daily cover in a sanitary landfill, South Korea. Waste management \& research : the journal of the International Solid Wastes and Public Cleansing Association, ISWA:734242X18806996

174. Zhang Y, Su G, Zheng L, Liu D, Guo Z, Wei P. 2018. The environmental friendliness of fuzzy-ball drilling fluids during their entire life-cycles for fragile ecosystems in coalbed methane well plants. Journal of hazardous materials 364:396-405

175. Cho HJ, Chen VT, Qiao S, Koo WT, Penner RM, Kim ID. 2018. Pt-Functionalized PdO Nanowires for Room Temperature Hydrogen Gas Sensors. ACS sensors 3:2152-8

176. Dinda S. 2018. A Computational Study of Enantioselectivity in the Asymmetric Allylation of Aldehydes with Chiral Pt(II) Phosphinite Complexes. The Journal of organic chemistry

177. Jeon SH, You Y, Jin H, Kim CU, Park YK, et al. 2019. Hydroupgrading of Bio-Oil Over PtMg/KIT-6 Catalysts. Journal of nanoscience and nanotechnology 19:1126-9

178. Knossalla J, Paciok P, Gohl D, Jalalpoor D, Pizzutilo E, et al. 2018. Shape-controlled nanoparticles in pore-confined space. Journal of the American Chemical Society

179. Kwon HC, Kim M, Grote JP, Cho SJ, Chung MW, et al. 2018. Carbon Monoxide as a Promoter of Atomically Dispersed Platinum Catalyst in Electrochemical Hydrogen Evolution Reaction. Journal of the American Chemical Society

180. L GV, Russell AE, Skylaris CK. 2018. Ethanol, O, and CO adsorption on Pt nanoparticles: effects of nanoparticle size and graphene support. Physical chemistry chemical physics : PCCP 20:25918-30

181. Li C, Yuan Q, Ni B, He T, Zhang S, et al. 2018. Dendritic defect-rich palladium-coppercobalt nanoalloys as robust multifunctional non-platinum electrocatalysts for fuel cells. Nature communications 9:3702

182. Li Z, Zhuang Z, Lv F, Zhu H, Zhou L, et al. 2018. The Marriage of the FeN4 Moiety and MXene Boosts Oxygen Reduction Catalysis: Fe 3d Electron Delocalization Matters. Advanced materials 30:e1803220

183. Majrik K, Paszti Z, Korecz L, Trif L, Domjan A, et al. 2018. Study of PtOx/TiO(2) Photocatalysts in the Photocatalytic Reforming of Glycerol: The Role of Co-Catalyst Formation. Materials 11

184. Nigam S, Majumder C. 2018. Single atom alloy catalyst for SO3 decomposition: enhancement of platinum catalyst's performance by $\mathrm{Ag}$ atom embedding. Nanoscale 
185. Oh A, Kim HY, Baik H, Kim B, Chaudhari NK, et al. 2018. Topotactic Transformations in an Icosahedral Nanocrystal to Form Efficient Water-Splitting Catalysts. Advanced materials:e1805546

186. Olu PY, Li Q, Krischer K. 2018. The True Fate of Pyridinium in the Reportedly PyridiniumCatalyzed Carbon Dioxide Electroreduction on Platinum. Angewandte Chemie 57:14769-72

187. Quiroz J, Barbosa ECM, Araujo TP, Fiorio JL, Wang YC, et al. 2018. Controlling Reaction Selectivity over Hybrid Plasmonic Nanocatalysts. Nano letters

188. Raja PMV, Esquenazi GL, Wright KD, Gowenlock CE, Brinson BE, et al. 2018. Aqueous electromigration of single-walled carbon nanotubes and co-electromigration with copper ions. Nanoscale 10:19628-37

189. Rao CNR, Chhetri M. 2018. Borocarbonitrides as Metal-Free Catalysts for the Hydrogen Evolution Reaction. Advanced materials:e1803668

190. Tooley CA, Gasperoni CH, Marnoto S, Halpern JM. 2018. Evaluation of Metal Oxide Surface Catalysts for the Electrochemical Activation of Amino Acids. Sensors 18

191. Wang H, Ge Y, Tan J, Hao L, Peng Z, et al. 2018. The effects of ash inside a platinum-based catalyst diesel particulate filter on particle emissions, gaseous emissions, and unregulated emissions. Environmental science and pollution research international

192. Wu JH, Shao FQ, Han SY, Bai S, Feng JJ, et al. 2018. Shape-controlled synthesis of welldispersed platinum nanocubes supported on graphitic carbon nitride as advanced visible-lightdriven catalyst for efficient photoreduction of hexavalent chromium. Journal of colloid and interface science 535:41-9

193. Zang X, Chen W, Zou X, Hohman JN, Yang L, et al. 2018. Self-Assembly of Large-Area 2D Polycrystalline Transition Metal Carbides for Hydrogen Electrocatalysis. Advanced materials:e1805188

194. Zhao H, Yao S, Zhang M, Huang F, Fan Q, et al. 2018. Ultra-Small Platinum Nanoparticles Encapsulated in Sub-50 nm Hollow Titania Nanospheres for Low-Temperature Water-Gas Shift Reaction. ACS applied materials \& interfaces 10:36954-60

195. Gelat P, Yang J, Akanji O, Thomas PJ, Hutchins D, et al. 2017. The dynamic excitation of a granular chain: Contact mechanics finite element analysis and experimental validation. The Journal of the Acoustical Society of America 141:4240

196. Head MG, Brown RJ. 2016. The activity of the Research Investments in Global Health study and ways forward within the global funding and policy landscape. BMC proceedings 10:59

197. Li S, Ren Y, Fu Y, Gao X, Jiang C, et al. 2018. Fate of artificial sweeteners through wastewater treatment plants and water treatment processes. PloS one 13:e0189867

198. Mizuki H, Abe R, Mikami T. 2017. Ultrastructural Changes during the Life Cycle of Mycoplasma salivarium in Oral Biopsies from Patients with Oral Leukoplakia. Frontiers in cellular and infection microbiology 7:403

199. Villegas-Mercado CE, Agredano-Moreno LT, Bermudez M, Segura-Valdez ML, Arzate H, et al. 2018. Cementum protein 1 transfection does not lead to ultrastructural changes in nucleolar organization of human gingival fibroblasts. Journal of periodontal research 53:63642

200. Watson K, Farre MJ, Leusch FDL, Knight N. 2018. Using fluorescence-parallel factor analysis for assessing disinfection by-product formation and natural organic matter removal efficiency in secondary treated synthetic drinking waters. The Science of the total environment 640-641:31-40

201. Zainul, R. (2016, December 18). Design and Modification of Copper Oxide Electrodes for Improving Conversion Coefficient Indoors Lights (PV-Cell) Photocells. https: //doi.org/10.31227 /osf.io/pgn84

202. Zainul, R. (2016, December 18). Design and Modification of Copper Oxide Electrodes for Improving Conversion Coefficient Indoors Lights (PV-Cell) Photocells. https://doi.org/10.31227/osf.io/pgn84 
203. Zainul, R. (2016, September 24). Determination of the half-life and the quantum yield of $\mathrm{ZnO}$ semiconductor photocatalyst in humic acid. https://doi.org/10.31227/osf.io/e8a9x

204. Febriani, S. S., Yolanda, T., Arianti, V. A., \& Zainul, R. (2018, September 2). A Review Solid Stated : Principles and Methode. https://doi.org/10.31227/osf.io/7us4x

205. Liza, Y. M., Yasin, R. C., Maidani, S. S., \& Zainul, R. (2018, September 29). SOL GEL : PRINCIPLE AND TECHNIQUE (A REVIEW).

https://doi.org/10.31227/osf.io/2cuh8

206. Zainul, R. (2016, November 19). Effect of Temperature and Particle Motion against the ability of ZnO Semiconductor Photocatalyst in Humic Acid. https://doi.org/10.31227/osf.io/wnygb

207. Dinata, A. A., Rosyadi, A. M., Hamid, S., \& Zainul, R. (2018, August 31). A Review CHEMICAL VAPOR DEPOSITION : PROCESS AND APPLICATION. https://doi.org/10.31227/osf.io/yfeau

208. Putri, D. F., Ritonga, H. M., Murdiati, V., \& Zainul, R. (2018, August 31). A REVIEW WHAT IS HYDROTHERMAL ?. https://doi.org/10.31227/osf.io/dm56c

209. Awalliyah, A., Ikhwan, H., Nugiasari, V., \& Zainul, R. (2018, August 31). A REVIEW PRINSIP DASAR MILLING DALAM SINTESIS MATERIAL. https://doi.org/10.31227/osf.io/9xsqe

210. Candani, D., Ulfah, M., Noviana, W., \& Zainul, R. (2018, September 1). A Review Pemanfaatan Teknologi Sonikasi. https://doi.org/10.31227/osf.io/uxknv

211. Fatimah, P., Jumalia, R., Novianti, E. R., \& Zainul, R. (2018, August 31). A REVIEW Teknik Blended : Prinsip dan Dasar-Dasar. https://doi.org/10.31227/osf.io/tm2w4

212. Zainul, R., Oktavia, B., Dewata, I., \& efendi, j. (2017, February 4). Studi Dinamika Molekular dan Kinetika Reaksi pada Pembelahan Molekul Air untuk Produksi Gas Hidrogen. https://doi.org/10.31227/osf.io/876s3

213. Zainul, R., Alif, A., Aziz, H., Arief, S., \& s. (2015, October 22). Photoelectrosplitting Water Mechanism at Carbon Electrode Surface using Indoor lights. https://doi.org/10.31227/osf.io/vcxq8

214. Zainul, R., Alif, A., Aziz, H., Arief, S., \& s. (2015, October 22). Photoelectrosplitting Water Mechanism at Carbon Electrode Surface using Indoor lights. https://doi.org/10.31227/osf.io/vcxq8

215. M., Yani, S. R., \& Zainul, R. (2017, September 4). Aktivasi Tanah Napa dan Pengaruhnya Terhadap Adsorpsi Ion Timbal (II)/ Pb2+. https://doi.org/10.31227/osf.io/ps523

216. P, O. M., A, L. G., S, A. Y. M., \& Zainul, R. (2018, September 1). A Review Grinding : Teknik dan Prinsip Dasar pada Pengolahan Material. https://doi.org/10.31227/osf.io/trv4q

217. H., Sanjaya, H., \& Zainul, R. (2016, August 30). Synthesis and Electrical Properties of ZnO-ITO and Al -ITO thin Film by Spin Coating Technique Through Sol Gel Process. https ://doi.org/10.31227/osf.io/unrt4

218. M., Sanjaya, H., \& Zainul, R. (2015, December 30). Characterization of napa soil and adsorption of $\mathrm{Pb}$ (II) from aqueous solutions using on column method. https://doi.org/10.31227/osf.io/t8fh9

219. chaidir, z., Fadjria, N., A., \& Zainul, R. (2016, December 5). ISOLATION AND MOLECULAR IDENTIFICATION OF FRESHWATER MICROALGAE IN MANINJAU LAKE WEST SUMATERA. https://doi.org/10.31227/osf.io/nbcuf

220. Chaidir, Z., Zainul, R., Nurakhbari, D., \& Salim, M. (2016, September 24). Optimization of Spirulina Platensis Culture for Antioxidant Production. https://doi.org/10.17605/OSF.IO/FD6E4 
221. Zainul R, Oktavia B, Dewata I, Efendi J. Thermal and Surface Evaluation on The Process of Forming a Cu2O/CuO Semiconductor Photocatalyst on a Thin Copper Plate. Proc. IOP Conference Series: Materials Science and Engineering, 2018, 335:012039: IOP Publishing

222. Zainul R, Alif A, Aziz H, Arief S, Dradjad S, Munaf E. 2015. Design of photovoltaic cell with copper oxide electrode by using indoor lights. RESEARCH JOURNAL OF PHARMACEUTICAL BIOLOGICAL AND CHEMICAL SCIENCES 6:353-61

223. Mawardi M, Deyundha D, Zainul R. Characterization of PCC Cement by Addition of Napa Soil from Subdistrict Sarilamak 50 Kota District as Alternative Additional Material for Semen Padang. Proc. IOP Conference Series: Materials Science and Engineering, 2018, 335:012034: IOP Publishing

224. Anhar A, Sumarmin R, Zainul R. 2016. Measurement of Glycemic Index of West Sumatera Local Rice Genotypes for Healthy Food Selection.

225. Zainul R, Dewata I. 2015. Determination of pH-BOD-COD and degradation in batang arau watersheds at Padang city.

226. Zainul R, Alif A, Aziz H, Arief S. 2015. DISAIN GEOMETRI REAKTOR FOTOSEL CAHAYA RUANG. Jurnal Riset Kimia 8:131

227. Zainul R, Alif A, Aziz H, Arief S, Darajat S. 2015. Modifikasi dan Karakteristik IV Sel Fotovoltaik Cu2o/Cu-Gel Na2so4 Melalui Iluminasi Lampu Neon. EKSAKTA 2:50

228. Yasthopi A. 2015. Photoelectrosplitting water for hydrogen production using illumination of indoor lights. Journal of Chemical and Pharmaceutical Research 7:246-56

229. Zainul R.2015. Disain dan Modifikasi Kolektor dan Reflektor Cahaya pada Panel Sel Surya $\mathrm{Al} / \mathrm{Cu} 2 \mathrm{O}-\mathrm{Gel} \mathrm{Na} 2 \mathrm{SO} 4$.

230. Mawardi Anwar E, Kosela S, Wibowo W, Zainul R. 2015. Study of Pb (II) biosorption from aqueous solution using immobilized Spirogyra subsalsa biomass. Journal of Chemical and Pharmaceutical Research 7:715-22

231. Desy Kurniawati I, Harmiwati SS, Chaidir Z, Munaf E. Rahmiana Zein, Hermansyah Aziz, Rahadian Zainul. 2015. Biosorption of $\mathrm{Pb}$ (II) from Aqueous Solutions Using Column Method by Lengkeng (Euphoria logan lour) Seed and Shell. Journal of Chemical and Pharmaceutical Research 7:872-7

232. Zainul R, Nurakhbari D, Salim M. Optimization of Spirulina Platensis Culture for Antioxidant Production.

233. Horiza, H., Azhar, M. and Efendi, J. (2017) "EKSTRAKSI DAN KARAKTERISASI INULIN DARI UMBI DAHLIA (Dahlia sp.L) SEGAR DAN DISIMPAN”, EKSAKTA: Berkala Ilmiah Bidang MIPA, 18(01), pp. 31-39. doi: https://doi.org/10.24036/eksakta/vol18-iss01/14.

234. Iryani, I., Iswendi, I. and Katrina, I. T. (2017) "UJI AKTIVITAS ANTI DIABETES MELLITUS SENYAWA METABOLIT SEKUNDER FRAKSI AIR DARI BERAS KETAN HITAM ( Oryza satival. Var glutinosa) PADA MENCIT PUTIH", EKSAKTA: Berkala Ilmiah Bidang MIPA, 18(01), pp. 54-60. doi: https://doi.org/10.24036/eksakta/vol18-iss01/17.

235. Suryelita, S., Etika, S. B. and Kurnia, N. S. (2017) "ISOLASI DAN KARAKTERISASI SENYAWA STEROID DARI DAUN CEMARA NATAL (Cupressus funebris Endl.)", EKSAKTA: Berkala Ilmiah Bidang MIPA, 18(01), pp. 86-94. doi: https://doi.org/10.24036/eksakta/vol18-iss01/23.

236. Iskandar, I., Horiza, H. and Fauzi, N. (2017) "EFEKTIVITAS BUBUK BIJI PEPAYA (Carica Papaya Linnaeaus) SEBAGAI LARVASIDA ALAMI TERHADAP KEMATIAN LARVA AEDES AEGYPTY TAHUN 2015", EKSAKTA: Berkala Ilmiah Bidang MIPA, 18(01), pp. 12-18. doi: https://doi.org/10.24036/eksakta/vol18-iss01/12. 
237. Ramli, R., Jonuarti, R. and Hartono, A. (2017) “ANALISIS STRUKTUR NANO DARI LAPISAN TIPIS COBALT FERRITE YANG DIPREPARASI DENGAN METODE SPUTTERING”, EKSAKTA: Berkala Ilmiah Bidang MIPA, 18(01), pp. 46-53. doi: https://doi.org/10.24036/eksakta/vol18-iss01/16.

238. Sanjaya, H. (2017) "DEGRADASI METHYLENE BLUE MENGGUNAKAN KATALIS ZnO-PEG DENGAN METODE FOTOSONOLISIS”, EKSAKTA: Berkala Ilmiah Bidang MIPA, 18(02), pp. 21-29. doi: https://doi.org/10.24036/eksakta/vol18-iss02/45.

239. NIngsih, S. K. (2017) "SINTESIS DAN KARAKTERISASI NANOPARTIKEL ZnO DOPED Cu2+ MELALUI METODA SOL-GEL", EKSAKTA: Berkala Ilmiah Bidang MIPA, 18(02), pp. 39-51. doi: https://doi.org/10.24036/eksakta/vol18-iss02/51.

240. Saiya, A. (2017) “ANALISIS RESIDU KLORPIRIFOS DALAM SAYURAN KUBIS DENGAN METODE HPLC DI BEBERAPA PASAR TRADISIONAL DI SULAWESI UTARA", EKSAKTA: Berkala Ilmiah Bidang MIPA, 18(02), pp. 77-85. doi: https://doi.org/10.24036/eksakta/vol18-iss02/57.

241. Syafei, N. (2017) "ANALISA FENOMENA KOROSI PELAT PIPA BAJA KARBON API 5L-X65 DALAM LARUTAN 250 ML ASAM ASETAT DAN 4750 ML AQUADES PADA KONDISI GAS CO2 DAN H2S JENUH PADA SUHU RUANG", EKSAKTA: Berkala Ilmiah Bidang MIPA, 18(02), pp. 113-120. doi: https://doi.org/10.24036/eksakta/vol18-iss02/63.

242. Tutuarima, T. (2017) "SIFAT FISIK DAN KIMIA MARMALADE JERUK KALAMANSI (Citrus microcarpa) : KAJIAN KONSENTRASI PEKTIN DAN SUKROSA Physical and Chemical Properties of Marmalade Citrus of Calamondin (Citrus microcarpa) : Study of Pectin and Sucrose Concentrations", EKSAKTA: Berkala Ilmiah Bidang MIPA, 18(02), pp. 164-172. doi: https://doi.org/10.24036/eksakta/vol18-iss02/73.

243. Ruswandi, R. (2018) "Determination of Fructose Content resulted by Inulin Hydrolysis with DNS as Oxidizer", EKSAKTA: Berkala Ilmiah Bidang MIPA, 19(1), pp. 14-23. doi: https://doi.org/10.24036/eksakta/vol19-iss1/102.

244. Sanjaya, H. (2018) "DEGRADASI METIL VIOLET MENGGUNAKAN KATALIS ZnO-TiO2 SECARA FOTOSONOLISIS”, EKSAKTA: Berkala Ilmiah Bidang MIPA, 19(1), pp. 91-99. doi: https://doi.org/10.24036/eksakta/vol19-iss1/131.

245. Hidayani, T. (2018) "GRAFTING POLIPROPILENA DENGAN MALEAT ANHIDRIDA SEBAGAI PENGIKAT SILANG DENGAN INISIATOR BENZOIL PEROKSIDA", EKSAKTA: Berkala Ilmiah Bidang MIPA, 19(1), pp. 56-62. doi: https://doi.org/10.24036/eksakta/vol19-iss1/127. 
246. Prabowo, H. (2018) "PENYELIDIKAN KELAYAKAN KIMIA DAN PENYEBARAN CADANGAN PASIR BESI DAERAH TIKU KABUPATEN AGAM UNTUK BAHAN BAKU SEMEN PADA PT. SEMEN PADANG”, EKSAKTA: Berkala Ilmiah Bidang MIPA, 19(1), pp. 39-42. doi: https://doi.org/10.24036/eksakta/vol19-iss1/121.

247. Syafei, N. (2018) "Riset Material ANALISA FENOMENA KOROSI PELAT PIPA BAJA KARBON API 5L-X65 DALAM LARUTAN 7900 ML AIR LAUT DAN 100 ML AMONIAK PADA KONDISI GAS CO2 DAN H2S JENUH PADA SUHU RUANG.", EKSAKTA: Berkala Ilmiah Bidang MIPA, 19(1), pp. 7-13. doi: https://doi.org/10.24036/eksakta/vol19-iss1/83.

248. Parbuntari, H., Prestica, Y., Gunawan, R., Nurman, M. and Adella, F. (2018) "Preliminary Phytochemical Screening (Qualitative Analysis) of Cacao Leaves (Theobroma cacao L.)", EKSAKTA: Berkala Ilmiah Bidang MIPA, 19(2), pp. 40-45. doi: https://doi.org/10.24036/eksakta/vol19-iss2/142.

249. Dinata, M. and Soehardi, F. (2018) "Factor Analysis of Physics Chemistry Waters that Affects Damage Safety Cliff on the Outskirts of River Siak", EKSAKTA: Berkala Ilmiah Bidang MIPA, 19(2), pp. 46-49. doi: https://doi.org/10.24036/eksakta/vol19-iss2/143.

250. Sofyanita, S. and Octaria, Z. (2018) "Fenthion Compound Degradation in the Pesticide Bayleton $500 \mathrm{ec}$ in Sonolysis, Ozonolysis and Sonozolysis with Addition of TiO2-anatase", EKSAKTA: Berkala Ilmiah Bidang MIPA, 19(2), pp. 70-79. doi: https://doi.org/10.24036/eksakta/vol19-iss2/153.

251. Harahap, F. and Lubis, L. (2018) "Analysis of Heavy Metals Distribution in the River Town of Hamasaki's Rod Padangsidimpuan”, EKSAKTA: Berkala Ilmiah Bidang MIPA, 19(2), pp. 50-56. doi: https://doi.org/10.24036/eksakta/vol19-iss2/149.

252. Syafei, N., Hidayat, D., Emilliano, E. and Men, L. (2018) “Analysis Cracking Corrosion on Carbon Steel Pipes API 5L-X65 In Solution $7700 \mathrm{ml}$ Aquades, $250 \mathrm{ml}$ Acetic Acid and $50 \mathrm{ml}$ Ammonia with Gas CO2 and H2S in Saturation Condition", EKSAKTA: Berkala Ilmiah Bidang MIPA, 19(2), pp. 21-31. doi: https://doi.org/10.24036/eksakta/vol19-iss2/138. 